

\section{RDI Development: Wisdom Way Solar Village, Greenfield, Massachusetts Field Test Report}

Technical Report NREL/TP-550-45865

May 2009

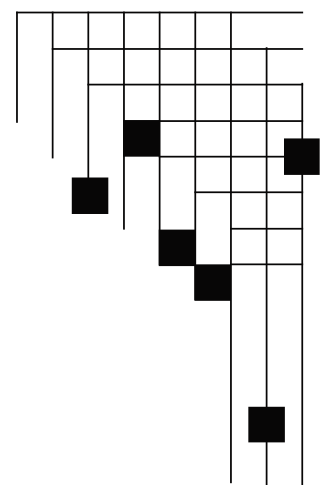

Prepared under Task No. BET98001

National Renewable Energy Laboratory 1617 Cole Boulevard, Golden, Colorado 80401-3393 303-275-3000 • www.nrel.gov

NREL is a national laboratory of the U.S. Department of Energy Office of Energy Efficiency and Renewable Energy

Operated by the Alliance for Sustainable Energy, LLC

Contract No. DE-AC36-08-GO28308 


\section{NOTICE}

This report was prepared as an account of work sponsored by an agency of the United States government. Neither the United States government nor any agency thereof, nor any of their employees, makes any warranty, express or implied, or assumes any legal liability or responsibility for the accuracy, completeness, or usefulness of any information, apparatus, product, or process disclosed, or represents that its use would not infringe privately owned rights. Reference herein to any specific commercial product, process, or service by trade name, trademark, manufacturer, or otherwise does not necessarily constitute or imply its endorsement, recommendation, or favoring by the United States government or any agency thereof. The views and opinions of authors expressed herein do not necessarily state or reflect those of the United States government or any agency thereof.

Available electronically at http://www.osti.gov/bridge

Available for a processing fee to U.S. Department of Energy and its contractors, in paper, from:

U.S. Department of Energy

Office of Scientific and Technical Information

P.O. Box 62

Oak Ridge, TN 37831-0062

phone: 865.576 .8401

fax: 865.576 .5728

email: mailto:reports@adonis.osti.gov

Available for sale to the public, in paper, from:

U.S. Department of Commerce

National Technical Information Service

5285 Port Royal Road

Springfield, VA 22161

phone: 800.553.6847

fax: 703.605.6900

email: orders@ntis.fedworld.gov

online ordering: http://www.ntis.gov/ordering.htm 


\section{Executive Summary}

On February 16-21, 2009, the National Renewable Energy Laboratory (NREL), Mountain Energy Partnership (a subcontractor of NREL), and the Consortium of Advanced Residential Buildings conducted short-term field tests on a house in the Wisdom Way Solar Village (G3, community scale, $40 \%$ savings level, cold climate). The house design features exceptionally tight construction, highly insulated envelopes, efficient ventilation and space heating design, and onsite renewable energy.

As the technical support for the U.S. Department of Energy Building America, NREL conducted field tests to verify that the prototype houses achieve the energy efficiency goal and maintain indoor air quality and comfort. Specifically, the Wisdom Way field test is targeted at verifying the performance of the point source heating, exhaust fan ventilation, and innovative distribution/transfer fan effectiveness in air and heat distribution.

Field test results showed that the exhaust ventilation fan, in conjunction with a distribution/transfer fan, provided good distribution of ventilation throughout all rooms in the three-bedroom test unit. However, the space heater, in conjunction with the distribution/transfer fan, is not sufficient to distribute the point heating throughout the house. We recommend supplementary heating backup in the upstairs bedrooms in addition to the point source heating system for acceptable comfort conditions.

We also recommend a better air seal gasket on the attic access door; more hot water draw tests when solar water heating systems are brought online, and long-term diagnostic monitoring of the solar water heating systems. 


\section{Contents}

Executive Summary .......................................................................................................................... iii

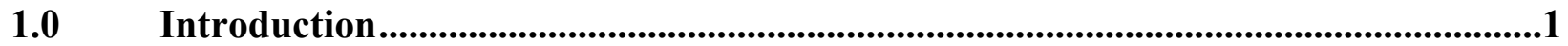

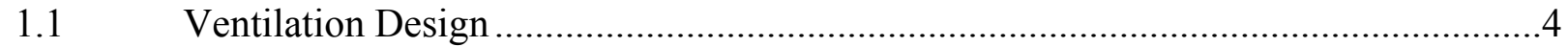

1.1.1 Exhaust Ventilation Versus Air Cycler - A Side-by-Side Comparison .........................

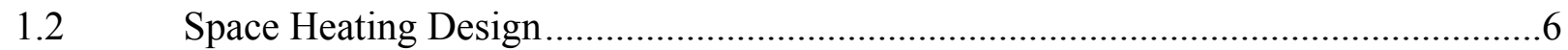

2.0 Field Test Plans and Research Questions ...................................................................7

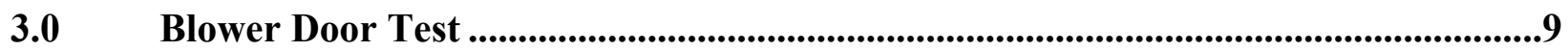

4.0 Tracer Gas Tests ............................................................................................................12

4.1 Air Exchange Rate - Concentration Decay Method (Case 0) ……...........................13

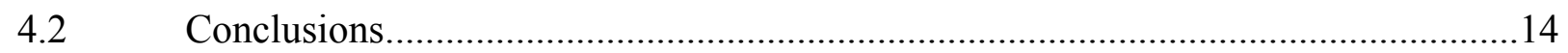

4.3 Age of Air - Concentration Decay Method (Cases 1-4) ...........................................14

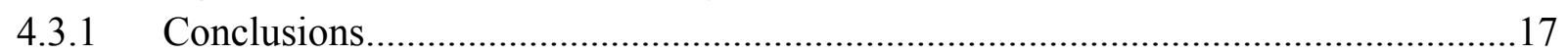

5.0 Room Temperature Measurements...............................................................................18

5.1 Overnight Temperature Distribution Measurements .................................................18

5.2 Thermal Imaging Test (Infrared Camera).................................................................23

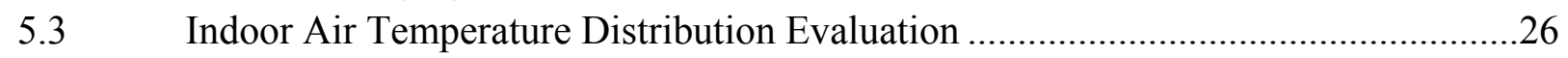

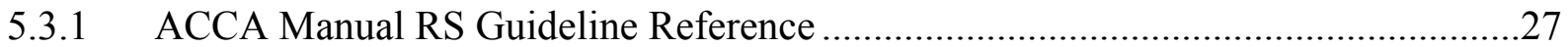

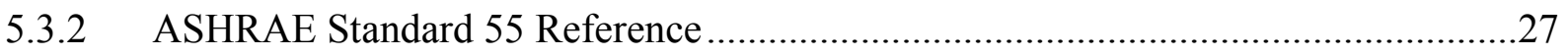

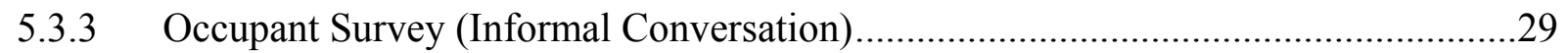

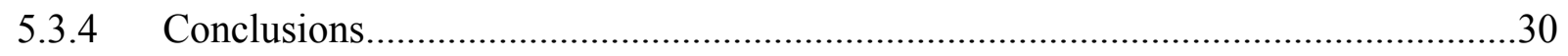

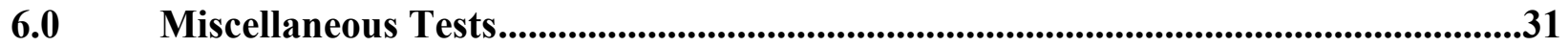

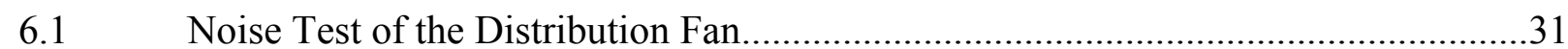

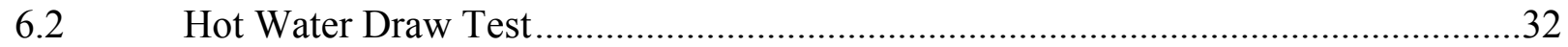

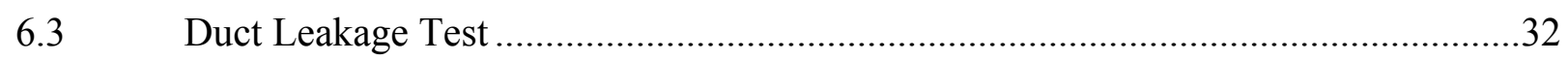

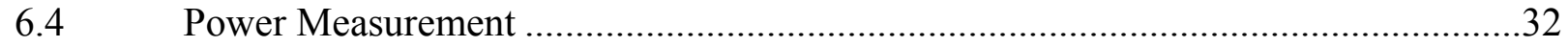

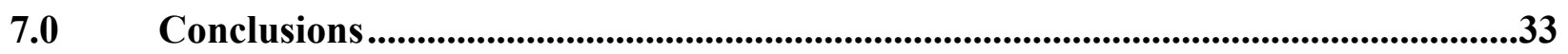

$8.0 \quad$ References....................................................................................................................34 


\section{Tables}

Table 1. Wisdom Way Solar Village Overall Specifications ............................................................

Table 2. Two Ventilation Systems: Side-by-Side Comparison ....................................................

Table 3. Test Matrix for Measuring Uniformity of Heating and Outside Air Distribution ..............7

Table 4. Blower Door Test Results for Two-Bedroom Unit (Guarded and Unguarded) ................9

Table 5. Blower Door Tests Results Calculations ....................................................................11

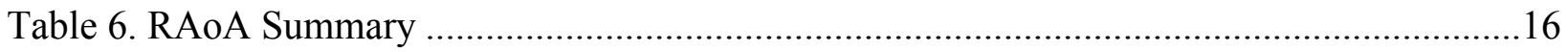

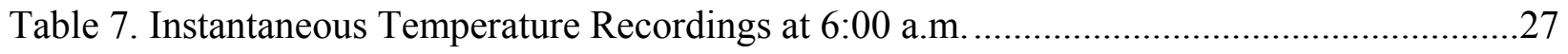

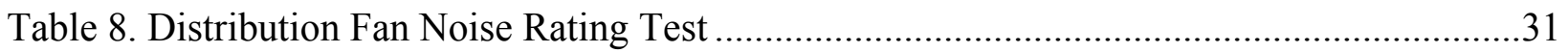

\section{Figures}

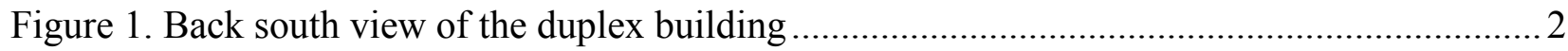

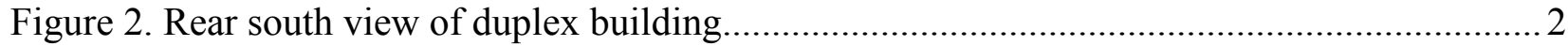

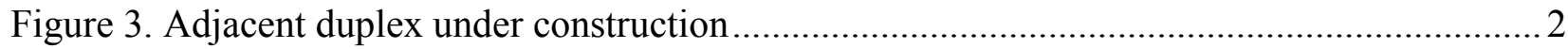

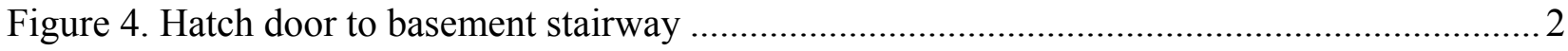

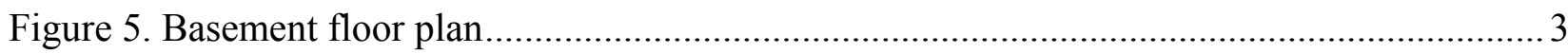

Figure 6. Basement northeast corner domestic hot water setup.................................................

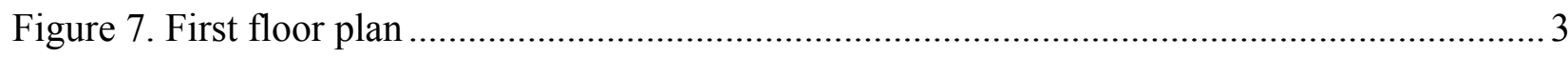

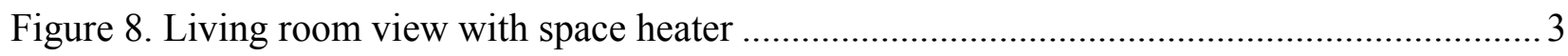

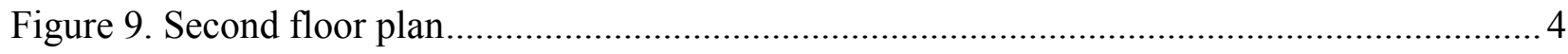

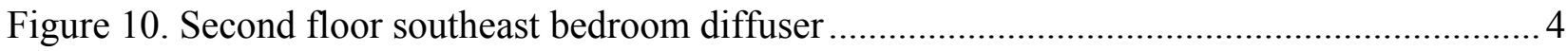

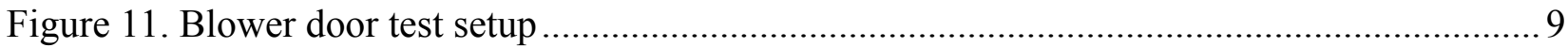

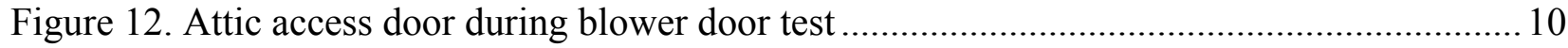

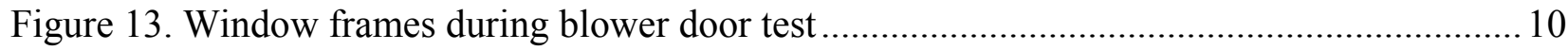

Figure 14. Central exhaust fan during blower door test.............................................................. 10

Figure 15. Basement door during blower door test..................................................................... 10

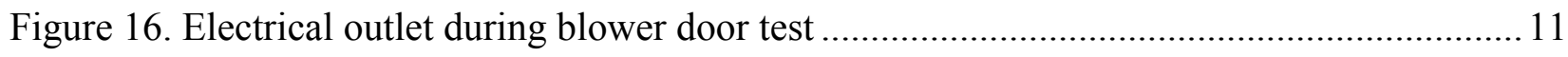

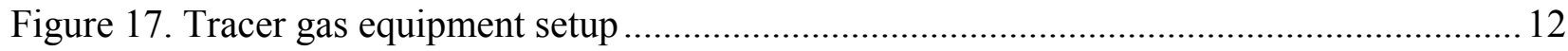

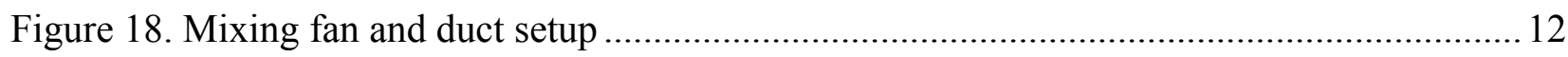

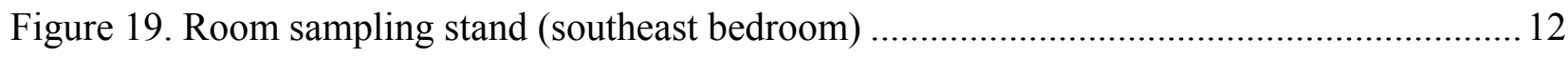

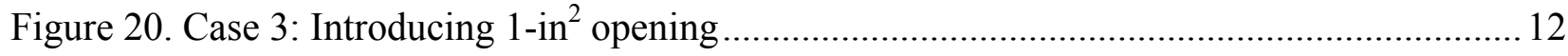

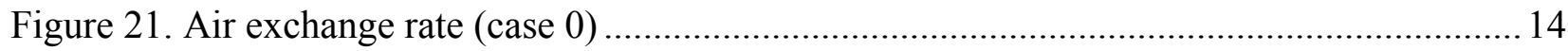

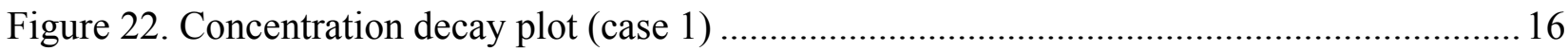

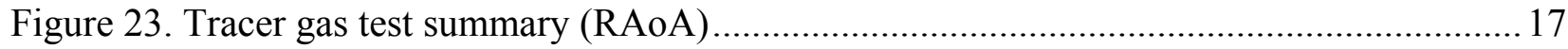

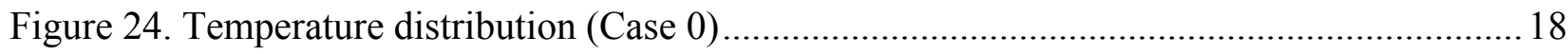


Figure 25. Temperature distribution overnight plot (Case 1) ............................................... 19

Figure 26. Temperature distribution overnight plot (Case 2) .................................................20

Figure 27. Temperature distribution overnight plot (Case 4) ...............................................2 21

Figure 28. Temperature distribution overnight plot (Case 5) ...............................................22

Figure 29. First-floor bathroom north corner thermal imaging ............................................ 24

Figure 30. Living room southwest corner thermal imaging ..................................................2 24

Figure 31 . First-floor north entry door thermal imaging ................................................. 24

Figure 32. First-floor east window framing thermal imaging...................................................25

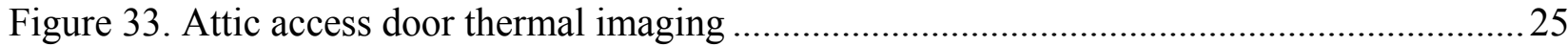

Figure 34. Southwest bedroom ceiling thermal imaging ....................................................25

Figure 35. Southeast bedroom distribution diffuser thermal imaging ....................................26

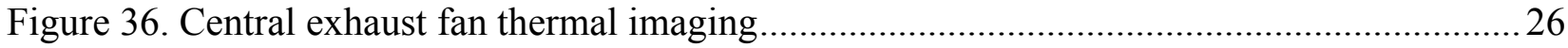

Figure 37. Northeast bedroom comfort estimate (occupant sleeping) ......................................28

Figure 38. Northeast bedroom comfort estimate (occupant seated) ........................................29

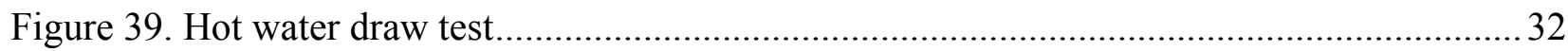




\subsection{Introduction}

Wisdom Way Solar Village is being built by RDI Development Inc. in Greenfield, Massachusetts. The village consists of 10 duplexes (20 units total, including two-, three-, and four-bedroom homes. As a G3 community in the U.S. Department of Energy Building America Initiative, the Wisdom Way Solar Village houses are predicted to achieve $40 \%$ whole-house source energy savings against the Building America benchmark. The house design features exceptionally tight construction, highly insulated building envelopes, efficient ventilation and space heating designs, and on-site renewable energy.

Table 1 shows design specifications. For a detailed description of the entire project, refer to CARB 2008 Annual Progress Report (BP1), Appendix X: Cold Climate Case Study - RDI Wisdom Way Solar Village [1]. (The descriptions of the house and the test unit all refer to the three-bedroom unit in the Lot 10 duplex building, unless specifically mentioned otherwise.)

Table 1. Wisdom Way Solar Village Overall Specifications

\begin{tabular}{|c|c|}
\hline Building & Lot 10 duplex \\
\hline Bedrooms & 2,3, or 4 bedrooms \\
\hline Floor area & $1,392 \mathrm{ft}^{2}$ for 3-bedroom units (not including basement) \\
\hline \multicolumn{2}{|l|}{ Construction } \\
\hline Foundation & Unconditioned basement; R-40 blown cellulose beneath the first floor. \\
\hline Exterior walls & $\begin{array}{l}\text { 12-in. double wall (double } 2 \times 4,16 \text {-in. OC) with R-43 dense-blown } \\
\text { cellulose }\end{array}$ \\
\hline Windows & $\begin{array}{l}\text { Triple-pane low-e, vinyl-framed windows from Paradigm on the north, } \\
\text { east, and west elevations; Paradigm double-pane low-e windows (lower } \\
\text { cost, higher solar heat gain coefficient) on the south }\end{array}$ \\
\hline Ceiling insulation & 14-in. blown-in cellulose insulation (R-50+) \\
\hline \multicolumn{2}{|c|}{ Miscellaneous Electrical Loads and Appliances } \\
\hline Lighting & $100 \%$ compact fluorescent lamps \\
\hline Appliances & ENERGY STAR $^{\circledR}$-rated refrigerator and dishwasher \\
\hline \multicolumn{2}{|l|}{ HVAC } \\
\hline Ventilation & $\begin{array}{l}\text { Efficient bathroom exhaust fan (Panasonic WhisperGreen) operating } \\
\text { continuously meeting ASHRAE } 62.2\end{array}$ \\
\hline $\begin{array}{l}\text { Distribution/transfer } \\
\text { fan }\end{array}$ & $\begin{array}{l}\text { Efficient mixing fan (Panasonic WhisperGreen) drawing air from first-floor } \\
\text { ceiling and distributing to each second-floor bedroom }\end{array}$ \\
\hline Space heating & $\begin{array}{l}\text { Sealed-combustion, natural gas-fired, through-the-wall unit heater in first- } \\
\text { floor open space; Monitor GF1800, } 83 \% \text { annual fuel utilization efficiency }\end{array}$ \\
\hline Space cooling & None \\
\hline Thermostat & Programmable thermostat on unit heater \\
\hline \multicolumn{2}{|c|}{ Domestic Hot Water } \\
\hline Water heating & $\begin{array}{l}\text { Solar hot water system with backup provided by a Rinnai tankless, } \\
\text { natural gas-fired, sealed combustion water heater ( } 0.82 \text { emissions factor) }\end{array}$ \\
\hline \multicolumn{2}{|c|}{ On-Site Renewable Energy } \\
\hline Solar thermal & $\begin{array}{l}2 \text { (for 2-bedroom units) or } 3 \text { (for 3- and 4-bedroom unit) flat-plate } 29 \mathrm{ft}^{2} \\
\text { collectors with 110-gallon storage tanks }\end{array}$ \\
\hline Solar electric & $\begin{array}{l}\text { 3.42-kW photovoltaic (PV) system for 3- and 4-bedroom units; } 2.85-\mathrm{kW} \\
\text { PV system for 2-bedroom unit }\end{array}$ \\
\hline
\end{tabular}


Figure 2 through Figure 4 show exterior views of the duplex (two units - two- and threebedroom units).

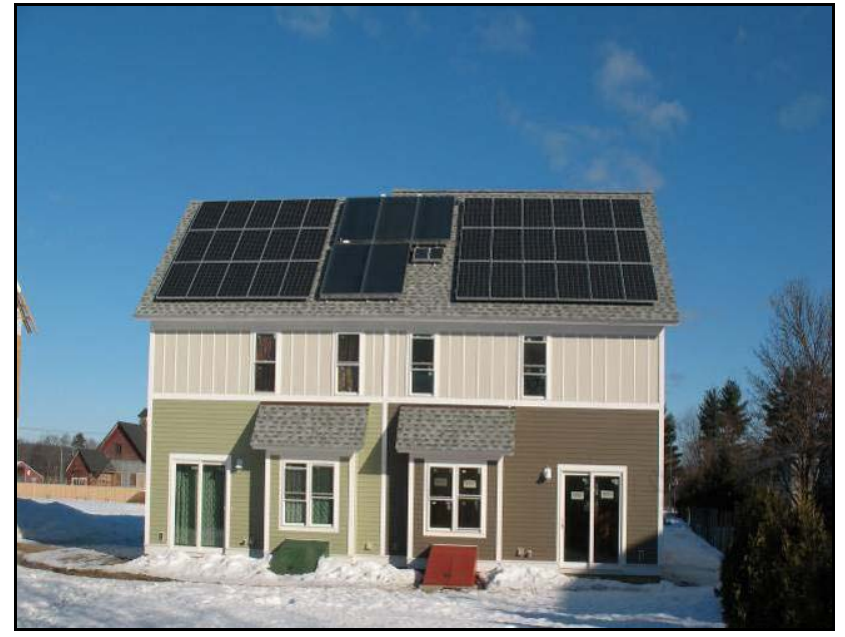

Figure 1. Back south view of the duplex building

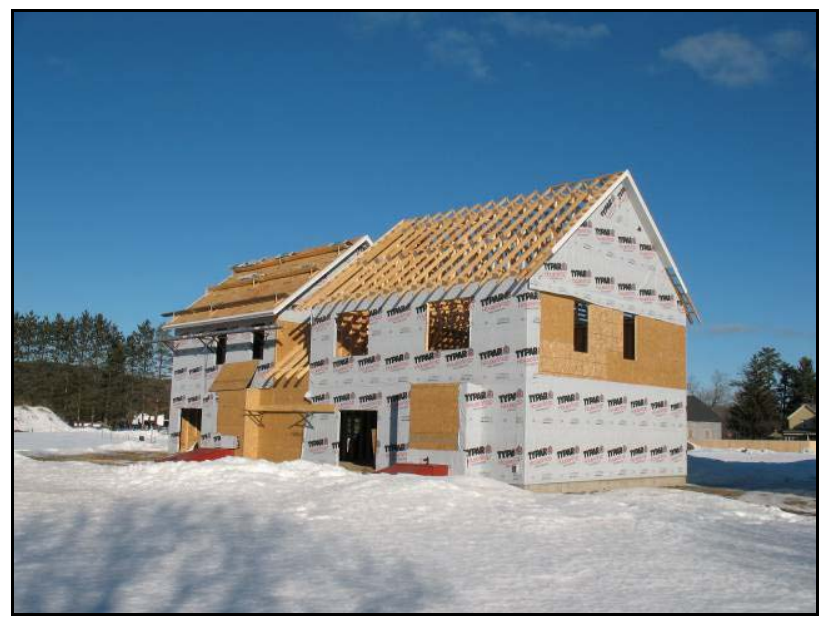

Figure 3. Adjacent duplex under construction

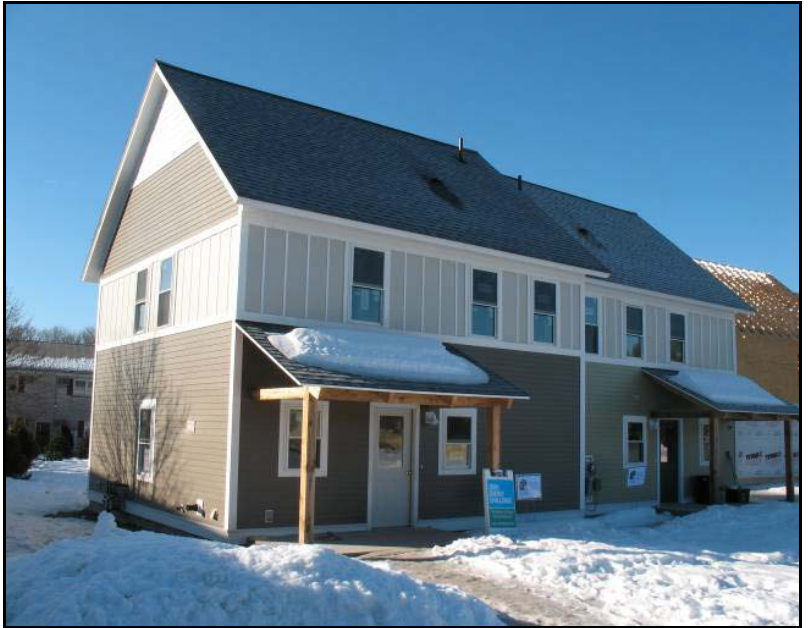

Figure 2. Front north view of the duplex building

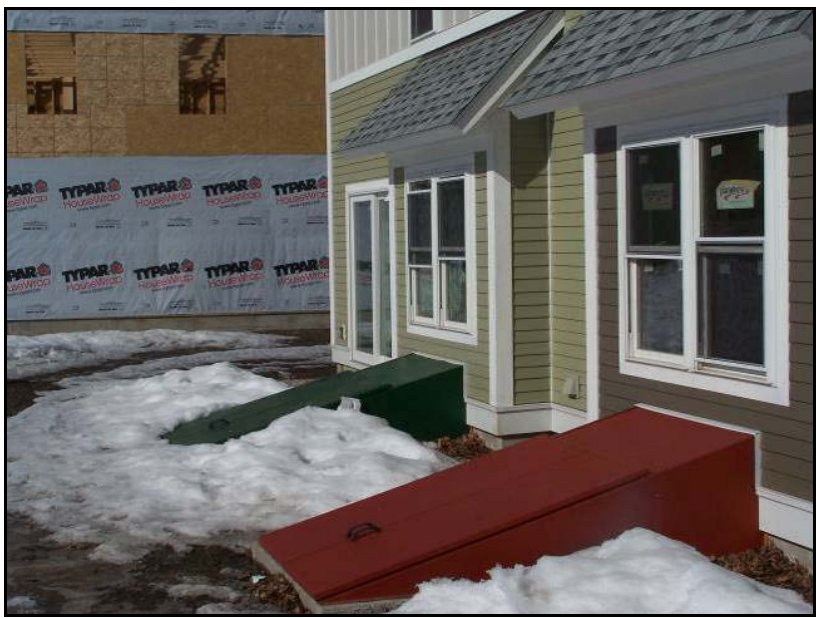

Figure 4. Hatch door to basement stairway

Figure 5 to Figure 10 show the test unit floor plans and corresponding pictures for the threebedroom unit. The red dots are tracer gas tests sampling points (see Section 5). 


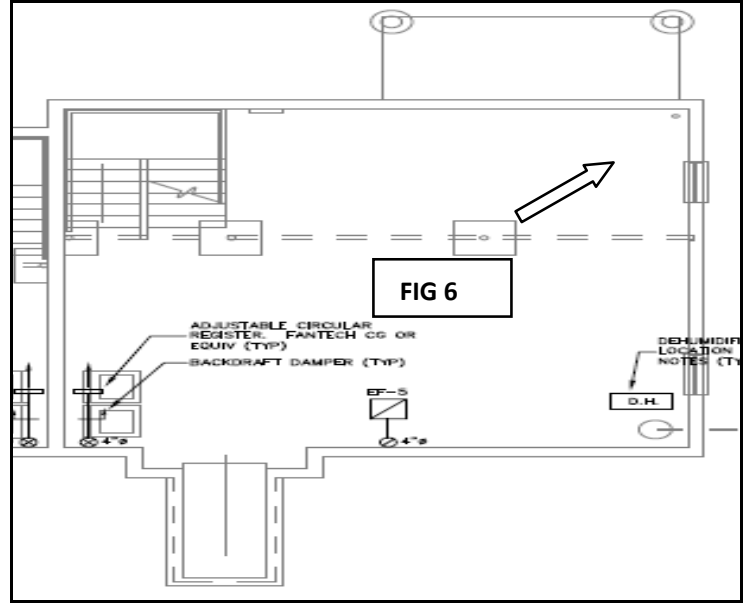

Figure 5. Basement floor plan

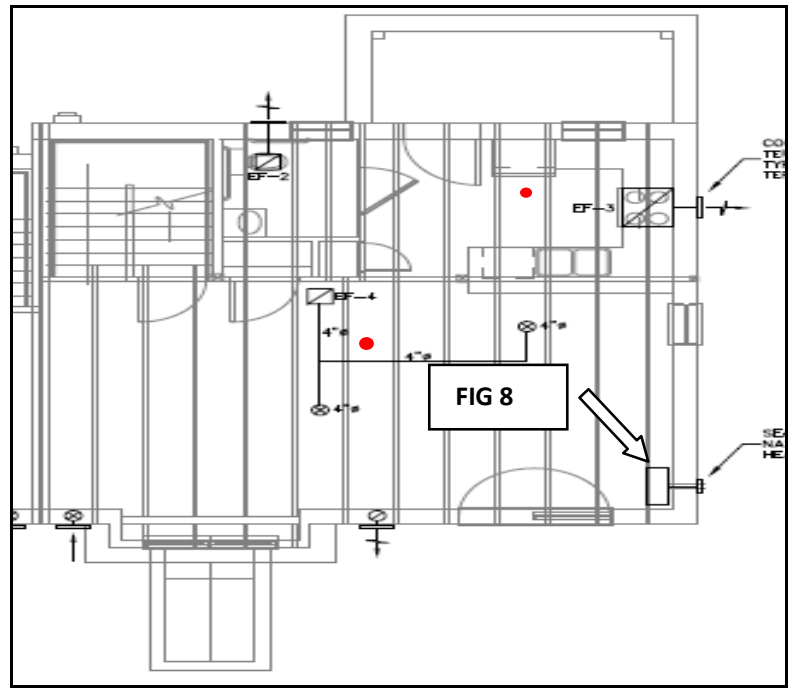

Figure 7. First floor plan

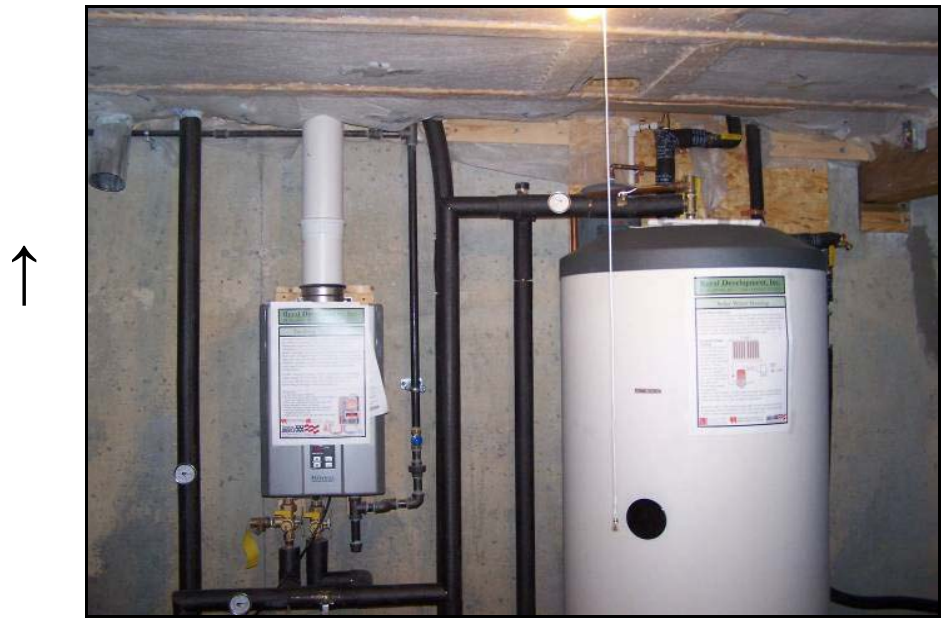

$\mathbf{N}$

Figure 6. Basement northeast corner domestic hot water setup

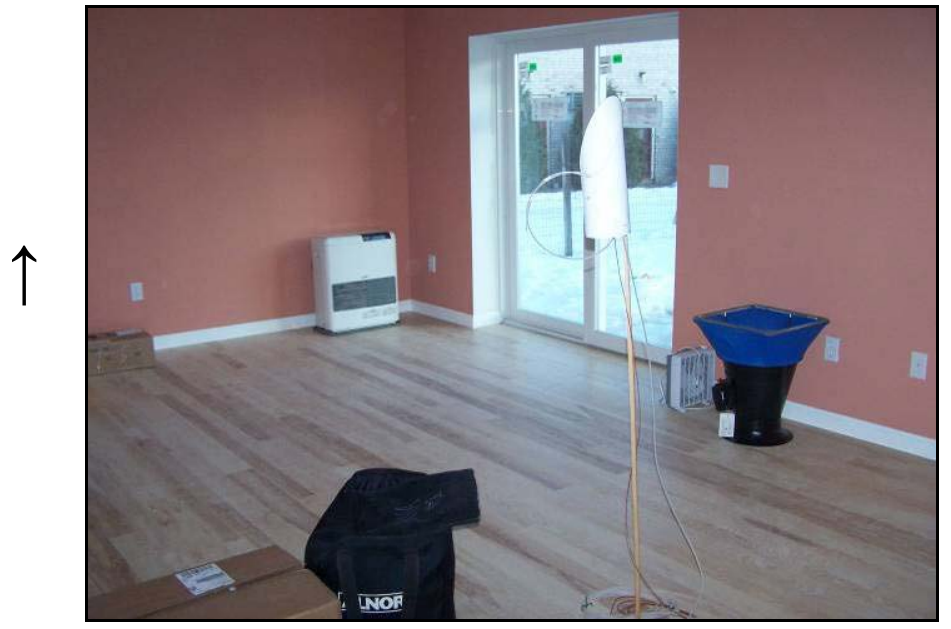

$\mathbf{N}$

Figure 8. Living room view with space heater 


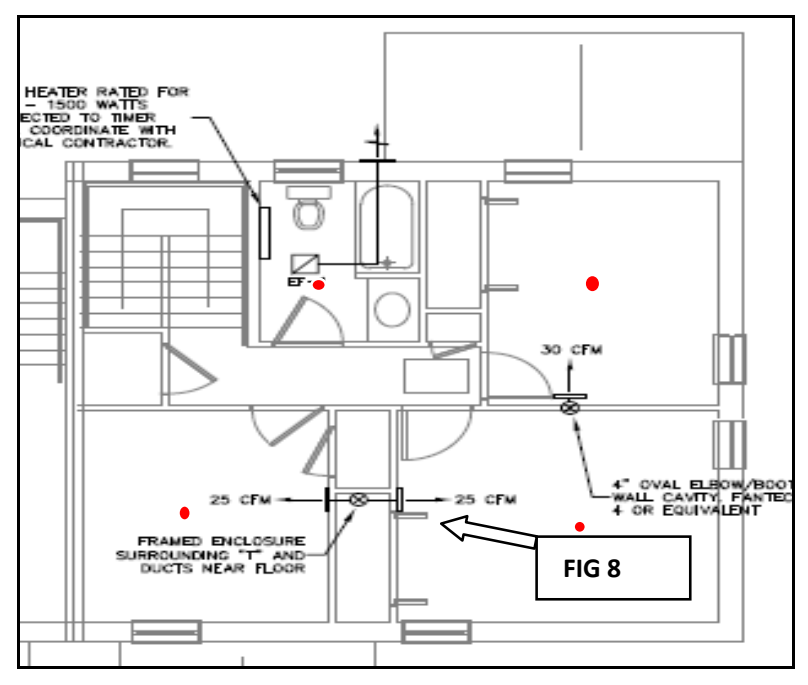

Figure 9. Second floor plan

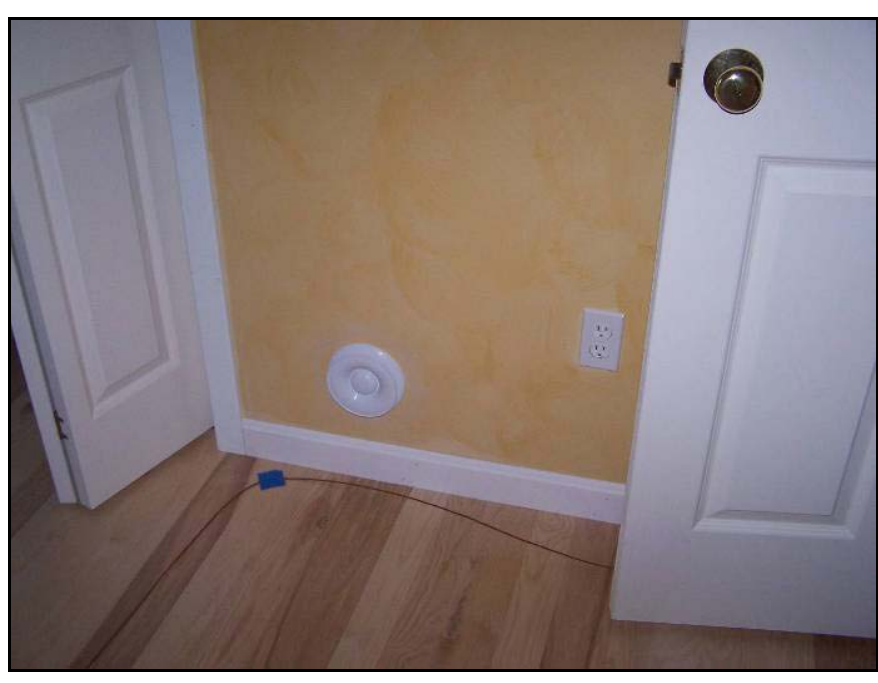

Figure 10. Second floor southeast bedroom diffuser

\subsection{Ventilation Design}

The mechanical ventilation requirement is achieved by a continuously operated central exhaust fan located in the second-floor main bathroom. This fan has an electronically commutated motor (ECM) and normally operates at low speed. When the occupant is in the bathroom, he or she can flip the wall switch to turn the fan to high speed. The field-tested low-speed flow is $47 \mathrm{cfm} @ 6$ W; high-speed flow is 72 cfm@14 W.

According to ASHRAE 62.2 [2], the mechanical ventilation rates are shown by the following equation:

$$
\mathrm{Q}_{\mathrm{FAN}} \quad=0.01 \mathrm{~A}_{\mathrm{FLOOR}}+7.5 \times\left(\mathrm{N}_{\mathrm{BR}}+1\right)
$$

Where:

$\begin{array}{lll}\mathrm{Q}_{\mathrm{FAN}} & = & \text { fan flow rate, } \mathrm{cfm} \\ \mathrm{A}_{\mathrm{FLOOR}} & = & \text { floor area, } \mathrm{ft}^{2} \\ \mathrm{~N}_{\mathrm{BR}} & = & \text { number of bedrooms }\end{array}$

Therefore:

$$
\mathrm{Q}_{\mathrm{FAN}}=0.01 \times 1,364+7.5 \times(3+1)=43 \mathrm{cfm}
$$

The continuously operated central exhaust fan for the Wisdom Way Solar Village house meets the requirement of ASHRAE 62.2.

To help with the uniform outside air distribution, the design incorporates a continuously operated distribution/transfer fan recessed under second-floor joists. This fan transfers the first-floor air and distributes it to every second-floor bedroom via 4-in. polyvinyl chloride (PVC) ducts. (The 
test unit has metal ducts installed. The rest of the community houses switched to PVC ducts for ease of installation with approval from the local building department.) Field-tested total supply flow to the bedrooms is $81 \mathrm{cfm}$, the first-floor fan grille intake flow is $90 \mathrm{cfm}$, and the fan power draw is $11 \mathrm{~W}$.

Two additional spot exhaust fans or hookups are installed in the house. The first-floor bathroom exhaust fan, which is controlled with a wall switch, field test flow was at $73 \mathrm{cfm} @ 17 \mathrm{~W}$. The kitchen has an opening (taped during test) for range and cook top exhaust.

\subsubsection{Exhaust Ventilation Versus Air Cycler - A Side-by-Side Comparison}

Table 2 shows a simple calculation that compares the operation of this central exhaust fan with a distribution/transfer fan versus a central fan integrated supply (CFIS) ventilation (33\% duty cycle) coupled with exhaust ventilation; specifically, the system used on the BSC Hilton Head Project. The CFIS system uses the central air handler fan for heating, cooling, and ventilation. To reduce the central air handler fan energy consumption, the design allows the central fan to run only one third of the hour when no heating or cooling is available, and supplements the remaining two thirds of the hour with a small bathroom exhaust fan. This ventilation concept is a hybrid of the exhaust ventilation and cycling central fan ventilation.

Table 2. Two Ventilation Systems: Side-by-Side Comparison

\begin{tabular}{|l|c||l|c|}
\hline \multicolumn{1}{|c|}{$\begin{array}{c}\text { RDI House Ventilation } \\
\text { System }\end{array}$} & $\begin{array}{c}\text { RDI Exhaust and } \\
\text { Transfer Fan } \\
\text { Continuously } \\
\text { Operated }\end{array}$ & $\begin{array}{c}\text { Hilton Head Ventilation } \\
\text { System }\end{array}$ & $\begin{array}{c}\text { CFIS (33\% Duty } \\
\text { Cycle) and } \\
\text { Coupled Exhaust } \\
\text { Ventilation }\end{array}$ \\
\hline $\begin{array}{l}\text { Ventilation (outdoor air) } \\
\text { provided (cfm) }\end{array}$ & 47 & $\begin{array}{l}\text { Ventilation (outdoor air) } \\
\text { provided (cfm) }\end{array}$ & 50 \\
\hline Distribution fan (W) & 17 & CFIS fan mode (W) & 120 \\
\hline $\begin{array}{l}\text { Exhaust fan power low } \\
\text { speed (W) }\end{array}$ & 6 & Coupled exhaust fan (W) & 6 \\
\hline $\begin{array}{l}\text { Exhaust fan power high } \\
\text { speed (W) }\end{array}$ & 14 & $\begin{array}{l}\text { Ventilation only operating } \\
\text { hours (total heating and } \\
\text { cooling hours) }\end{array}$ & 4,900 \\
\hline $\begin{array}{l}\text { Exhaust fan low speed } \\
\text { operating hours }\end{array}$ & 8,585 & $\begin{array}{l}\text { CFIS fan operating time in } \\
\text { ventilation only mode } \\
\text { (hours) }\end{array}$ & 1,617 \\
\hline $\begin{array}{l}\text { Exhaust fan high speed } \\
\text { operating hours }\end{array}$ & 175 & $\begin{array}{l}\text { Exhaust fan operating hours } \\
\text { in ventilation only mode } \\
\text { (hours) }\end{array}$ & 3,283 \\
\hline Distribution fan kWh/year & 149 & CFIS fan kWh/year & 194 \\
\hline Exhaust fan kWh/year & 54 & Exhaust fan kWh/year & 20 \\
\hline $\begin{array}{l}\text { Total Ventilation Fan } \\
\text { kWh/year }\end{array}$ & $\mathbf{2 0 3}$ & $\begin{array}{l}\text { Total Ventilation Fan } \\
\text { kWh/year }\end{array}$ & $\mathbf{2 1 4}$ \\
\hline
\end{tabular}

These two systems are comparable and operate efficiently for mechanical ventilation. 


\subsection{Space Heating Design}

Because of the highly insulated envelopes, the Consortium for Advanced Residential Buildings (CARB) used a low-cost system approach for the space heating system. Point source heating scheme is expected to work for this tightly constructed, highly insulated, and small footprint living space.

Space heating for the entire test unit is provided by the living room heater (Figure 7 and Figure 8). The Monitor GF1800 heater has a two-speed fan coupled with two-stage firing. The lowspeed fan flow is $133 \mathrm{cfm}$ at $10,200 \mathrm{Btu} \cdot \mathrm{h}$ firing output; the high-speed fan flow is $176 \mathrm{cfm}$ at $16,000 \mathrm{Btu} \cdot \mathrm{h}$ firing output. The heater remains at low-speed and low-stage firing when the space temperature remains within $\pm 2^{\circ} \mathrm{F}$ dead band of the set point. The heater adjusts to high-speed and high-stage firing when the temperature dead band widens $\left( \pm 5^{\circ} \mathrm{F}\right)$.

During the tests, the first-floor living room temperature set point is $70^{\circ} \mathrm{F}$. Natural stack effect will drive the warm air from the first floor to the second floor. The distribution/transfer fan is incorporated to distribute the first-floor warm air to each bedroom. The supply flow rate is $21-24$ $\mathrm{cfm}$ to each bedroom. The master bathroom has a 500-W baseboard heater that the occupant can turn on for showering. No supplemental heaters are installed in the upstairs bedrooms.

The second-floor bedrooms (where occupants sleep with doors closed) can raise issues for thermal comfort. Of particular concern is the northeast bedroom.

ASHRAE 55 [3] and ACCA Manual RS [4] are referenced for thermal comfort evaluation and compliance. 


\subsection{Field Test Plans and Research Questions}

As the technical support for the Building America program, NREL conducted field tests to verify that the prototype houses achieve the energy efficiency goal and maintain indoor air quality and comfort. Specifically, the Wisdom Way house field test verified the performance of the point source heating, exhaust fan ventilation, and the innovative distribution/transfer fan effectiveness in air and heat distribution.

Research questions were asked about airtightness, indoor air quality, and indoor temperature distributions before the field tests were conducted. These questions are the guidelines behind the field tests. The research questions from the test plan draft follow:

Q.1. What is the effective leakage area (ELA) of each unit as measured with a blower door? How does this change when the adjacent unit is also pressurized (guarded)? Do the ELAs to the adjacent unit and to the outside both meet the design targets? Is the fraction of ELA in the attached wall small enough $(<10 \%$ of total leakage area) that the Reciprocal Age-ofAir (RAoA) methodology can provide accurate results when only one unit is tested? Approximately how much error is introduced into the RAoA calculations?

Q.2. What is the air leakage of the distribution system? What are the installed flow rates of the ventilation and air distribution fans? What are the supply and exhaust flow rates of the distribution system? What are the power draws of the ventilation and air distribution fans in each operating state? Do all these quantities meet the design targets?

Q.3. What is the hourly air change rate of one unit in the duplex with and without the ventilation system running, as measured using a single-zone tracer gas test? Approximately what fraction is to the outside?

Q.4. What are the temperatures in various rooms throughout the duplex over consecutive 24hour periods with each condition shown in Table 3? Does a central point in each room meet the ASHRAE Standard 55 comfort recommendations at various times during each test? Are there any noticeable hot or cold spots on interior surfaces, as measured using an infrared (IR) camera? Do temperature differentials between rooms meet ACCA Manual RS guidelines $\left(4^{\circ} \mathrm{F}\right.$ maximum $)$ ?

Table 3. Test Matrix for Measuring Uniformity of Heating and Outside Air Distribution

\begin{tabular}{|c|c|c|c|}
\hline Case \# & Doors & $\begin{array}{c}\text { Exhaust } \\
\text { Fan }\end{array}$ & Distribution/Transfer Fan \\
\hline 1 & Closed & On & On \\
\hline 2 & Closed & On & Off \\
\hline 3 & Closed, see Q.5 & On & Off \\
\hline 4 & Open & On & On \\
\hline
\end{tabular}

Q.5. Using one unit of the duplex as the test space, what are the differences in outside air distribution (RAoA) throughout, using the operating conditions shown in Table 4? How 
does the outside air distribution change in Case 3 if a small opening $\left(1 \mathrm{in}^{2}{ }^{2}\right)$ is created in each bedroom to help control the location of outside air entry?

Q.6. What is the estimated difference in energy use for the installed heating and air distribution system compared to a small central furnace of similar efficiency, with an ECM motor and an AirCycler for air distribution?

Q.7. Does the solar water heating system operate as expected, based on simple commissioning tests?

Q.8. Based on the test results from the BSC Hilton Head project, and the solar domestic hot water (DHW) system design and climate for the RDI project, how often can the occupants expect hot water draws to be unmet by the tankless water heater with solar preheating?

Q.9. What are the heating temperature settings in each unit under occupied conditions?

Q.10.What are the room-to-room temperature differences under occupied conditions? Are the occupants satisfied with the temperature uniformity? 


\subsection{Blower Door Test}

One blower door test was performed in November 2008 on the two- and three-bedroom units. Both guarded (units depressurized to $50 \mathrm{~Pa}$ ) and unguarded (the two-bedroom unit depressurized to $50 \mathrm{~Pa}$ and the three-bedroom unit held at $50 \mathrm{~Pa}$ ) blower door tests were performed. The concern was to check and ensure minimal leakage between the units through the party wall. From the two-bedroom unit test record, party wall leakage was minimal (see Table 4).

The November blower door test also calculated an ELA@4 Pa=13.7 in. ${ }^{2}$ (guarded) and ELA @ $4 \mathrm{~Pa}=13.5$ in. $^{2}$ (unguarded) in the two-bedroom unit. The resulting party wall leakage is 0.2 in. ${ }^{2}$ The air leakage between the two units through the party wall is negligible, especially when the adjacent unit is maintained at close temperatures to the test unit. This guarantees the minimal number of errors introduced into RAoA calculations (Research Question Q.1).

Table 4. Blower Door Test Results for Two-Bedroom Unit (Guarded and Unguarded)

\begin{tabular}{|c|c|c|c|}
\hline $\begin{array}{c}\text { House } \\
\text { Pressure } \\
\text { (Pa) }\end{array}$ & $\begin{array}{c}\text { Unguarded Without Three- } \\
\text { Bedroom Unit (Same Pressure } \\
\text { Infiltration) } \\
\text { (cfm) }\end{array}$ & $\begin{array}{c}\text { Guarded With Three-Bedroom } \\
\text { Unit (Same Pressure } \\
\text { Infiltration) } \\
\text { (cfm) }\end{array}$ & $\begin{array}{c}\text { Difference/Party } \\
\text { Wall Leakage } \\
\text { (cfm) }\end{array}$ \\
\hline 60 & 338 & 291 & 48 \\
\hline 50 & 297 & 257 & 39 \\
\hline 40 & 253 & 222 & 31 \\
\hline 20 & 154 & 139 & 14 \\
\hline 10 & 93 & 88 & 6 \\
\hline
\end{tabular}

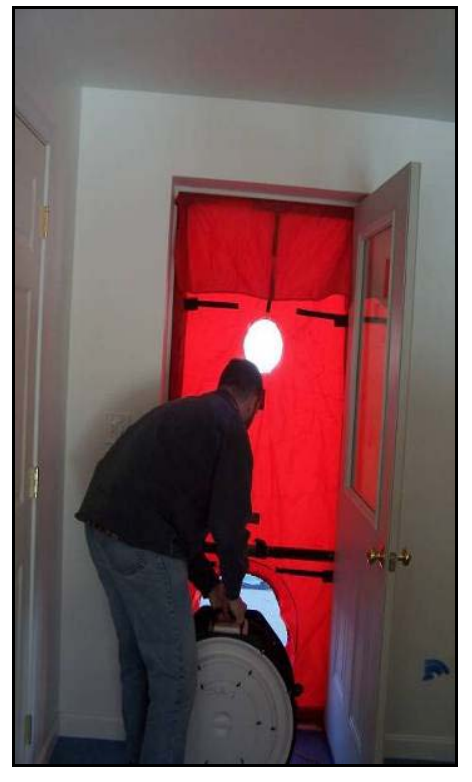

Figure 11. Blower door test setup
In November 2008, the three-bedroom unit was not finished and had some unwanted envelope leakages. Another blower door test was performed on February 16, 2009, for the three-bedroom test unit only (see Figure 11). The central exhaust fan and associated distribution fan were turned off to estimate the airtightness of the envelope without the mechanical ventilation impact.

Figure 12 through Figure 16 are the IR pictures taken during the walkthrough during the blower door test to help detect major leakage areas. Leakages were detected at the attic access door, the first-floor door leading to the basement, and the bathroom exhaust fans. There was also some leakage through walls and window cracks and electrical outlets (see Figure 13 and Figure 16). 


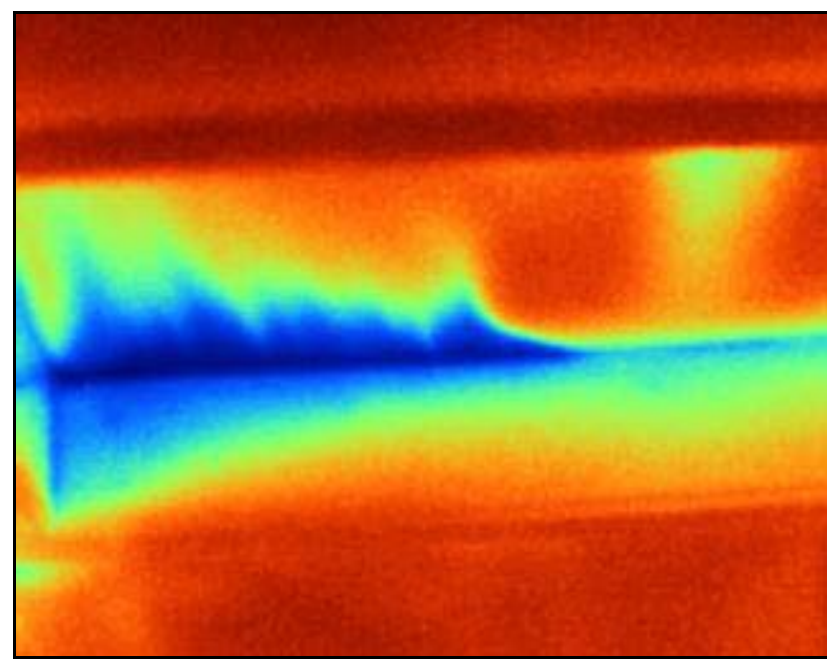

Figure 12. Attic access door during blower door test

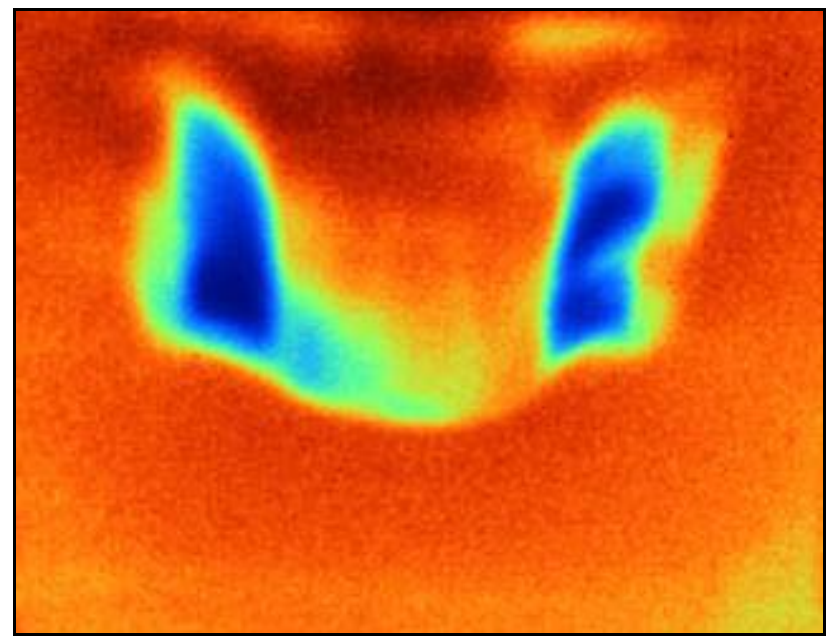

Figure 14. Central exhaust fan during blower door test

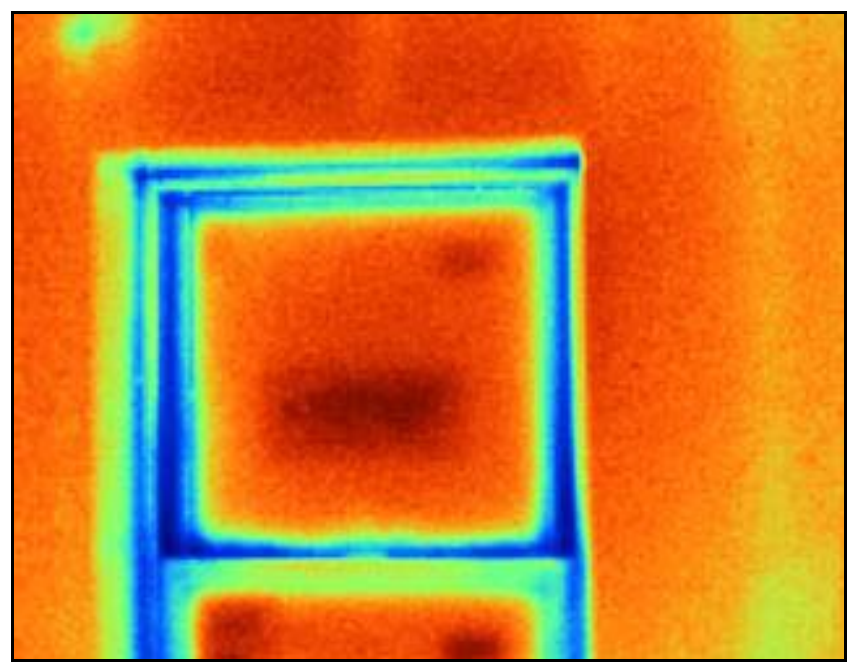

Figure 13. Window frames during blower door test

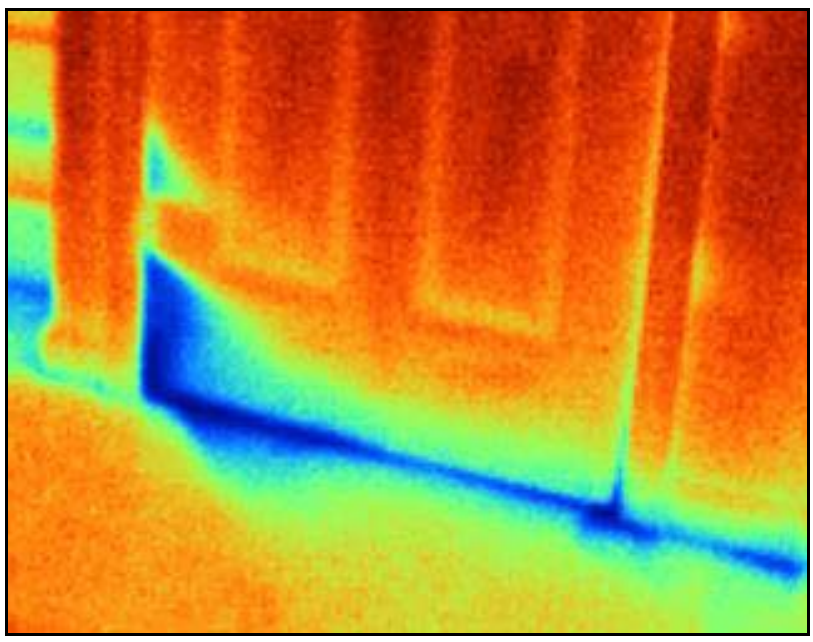

Figure 15. Basement door during blower door test 


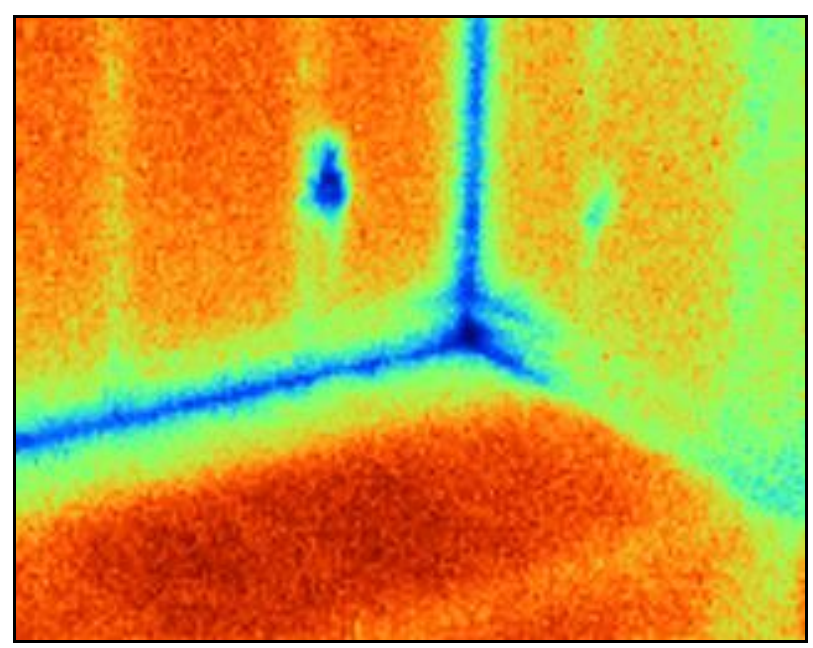

Figure 16. Electrical outlet during blower door test

Table 5 summarizes the blower door test results. According to Pennsylvania Housing Research Center (PHRC) [6] data, a tight house is one that has a natural infiltration air change rate $\left(\mathrm{ACH}_{n a t}\right)$ of less than 0.35 . The field test house $\mathrm{ACH}_{\text {nat }}$ is 0.07 . It is exceptionally low.

Table 5. Blower Door Tests Results Calculations

\begin{tabular}{|c|c|c|c|c|c|c|c|}
\hline \multicolumn{3}{|c|}{} & \multicolumn{3}{c|}{ @ 4 Pa } & @10 Pa & $\begin{array}{c}\text { @ Average Natural } \\
\text { Conditions Year } \\
\text { Round }\end{array}$ \\
\hline $\begin{array}{c}\text { Air } \\
\text { Flow }\end{array}$ & $\begin{array}{c}\text { Air } \\
\text { Change } \\
\text { Rate }\end{array}$ & $\begin{array}{c}\text { ELA } \\
\text { (in. }{ }^{2} \text { ) }\end{array}$ & Air Flow & $\begin{array}{c}\text { Air } \\
\text { Change } \\
\text { Rate }\end{array}$ & $\begin{array}{c}\text { ELA } \\
\left.\text { (in. }{ }^{2}\right)\end{array}$ & $\begin{array}{c}\text { EqLA } \\
\text { Canada* } \\
\text { (in. }^{2} \text { ) }\end{array}$ & Air Change Rate \\
\hline $\mathrm{CFM}_{50}$ & $\mathrm{ACH}_{50}$ & $\mathrm{ELA}_{50}$ & $\mathrm{CFM}_{4}$ & $\mathrm{ACH}_{4}$ & $\mathrm{ELA}_{4}$ & $\mathrm{ELA}_{10 \text { Canada }}$ & $\mathrm{ACH}_{\text {nat }}$ \\
\hline 273 & 1.5 & 22.0 & 39 & 0.22 & 11.2 & 23.3 & 0.07 \\
\hline
\end{tabular}

Floor Area $A_{\mathrm{flr}}=1,364 \mathrm{ft}^{2}$, Envelope Surface Area $A_{\text {env }}=4,528 \mathrm{ft}^{2}$, Volume $\mathrm{V}=10,912 \mathrm{ft}^{2}$

${ }^{*}$ EqLA - Equivalent Leakage Area 


\subsection{Tracer Gas Tests}

Five cases of tracer gas field tests were performed to evaluate: the air exchange rate of the entire test unit (Case 0 ) and the room-to-room distribution of the outside air (Cases 1 to 4 ). In all cases, the single-tracer concentration decay method $[4,5]$ was used with multiple sampling points. Figure 17 through Figure 20 show the field test setup.

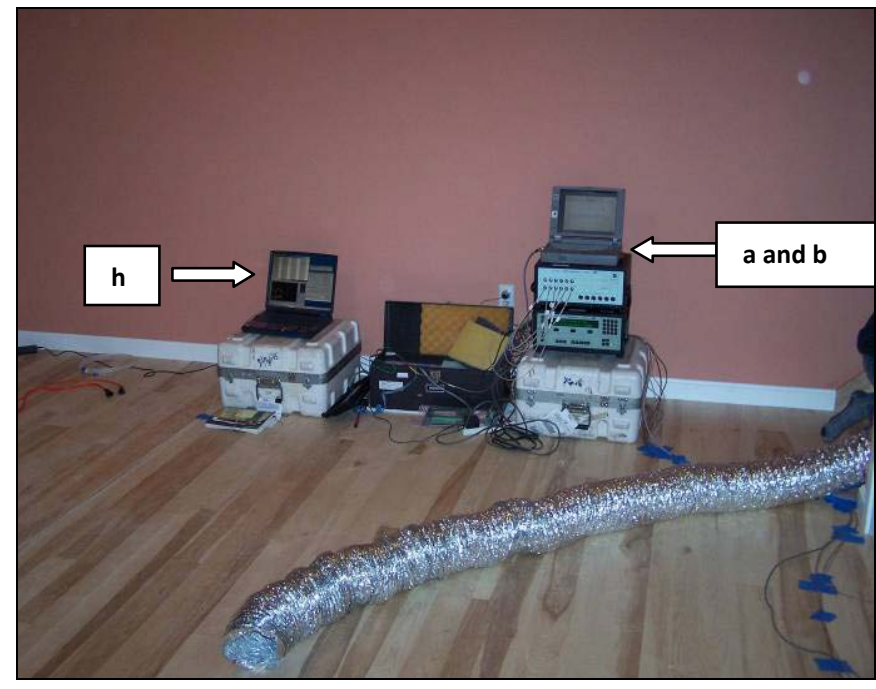

Figure 17. Tracer gas equipment setup

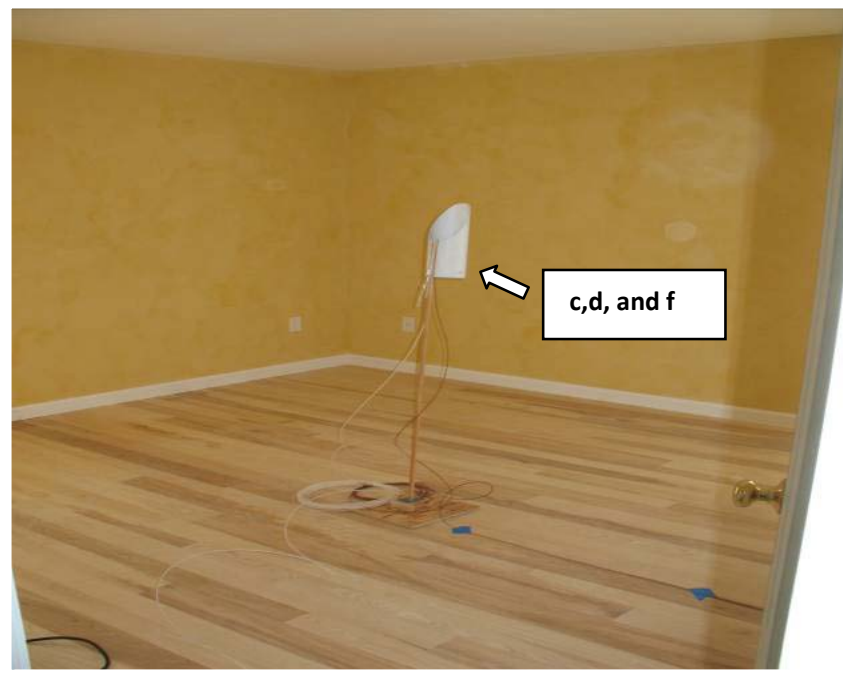

Figure 19. Room sampling stand (southeast bedroom)

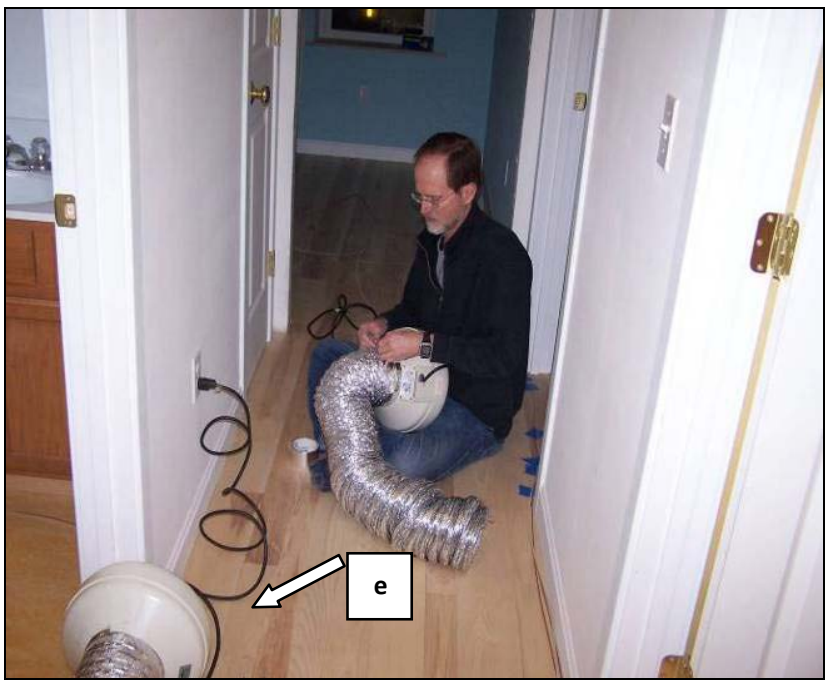

Figure 18. Mixing fan and duct setup

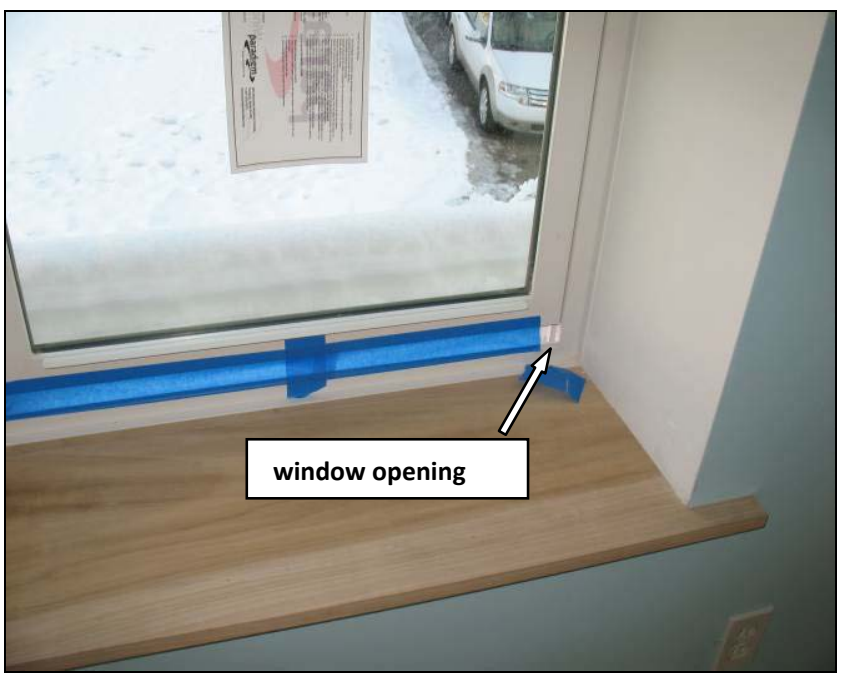

Figure 20. Case 3: Introducing 1-in ${ }^{2}$ opening

A brief description of the test equipment follows:

a. Gas analyzer

b. Multipoint sampler

c. Tubing for gas sampling, compatible with the multipoint sampler and the tracer gas 
d. Wooden stands to position the sampling points near the center of each room

e. Interzonal mixing fans

f. Room temperature sensors

g. Weather station: outdoor temperature and wind speed sensors with datalogger

h. Computer and software compatible

i. Tracer gas (SF 6).

Six sampling points were installed in the central location of the following rooms (see Figure 7 and Figure 9).

- First-floor living room (Living)

- First-floor kitchen (Kitchen)

- Second-floor northeast bedroom (NE BR)

- Second-floor southeast bedroom (SE BR)

- Second-floor southwest bedroom (SW BR)

- Second-floor main bathroom (Bath)

The basement was not dosed or heated during the tracer gas tests. The first-floor door to the basement was closed but not taped. The door is designed with a spring-latch mechanism that minimizes the door undercut gap when the door closed. Figure 15 shows some leakage through the basement door gap during the blower door test. This may introduce some error into our analysis. For now, this is not counted.

The two-bedroom unit homeowner was on vacation during the field test. That unit has temperature setting of $60^{\circ}-62^{\circ} \mathrm{F}$ (according to later meeting with homeowner). But the concern for additional error introduced into the test is minimal because the party wall leakage between the two- and three-bedroom units is minimal $\left(0.2 \mathrm{in}^{2}{ }^{2}\right)$. The party wall is also well insulated with $8-10$ in. of cellulose.

\subsection{Air Exchange Rate - Concentration Decay Method (Case 0)}

The air exchange rate - concentration decay method test began with injecting the tracer gas and mixing it uniformly throughout the house. Then the injection ceased but the interzonal mixing fans ran continuously throughout the measurement period (well-mixed condition). All bedroom doors were left open to help with mixing. A single gas analyzer with tubing to each sampling point was used to monitor the concentration of the tracer gas as it decayed.

The central exhaust ventilation fan was turned on for the first several hours, and then turned off for the remaining test period. Outside air temperatures were $22^{\circ}-37^{\circ} \mathrm{F}$ during the test period; the average wind speed was $0.2 \mathrm{mph}$. Figure 21 shows the test results. 


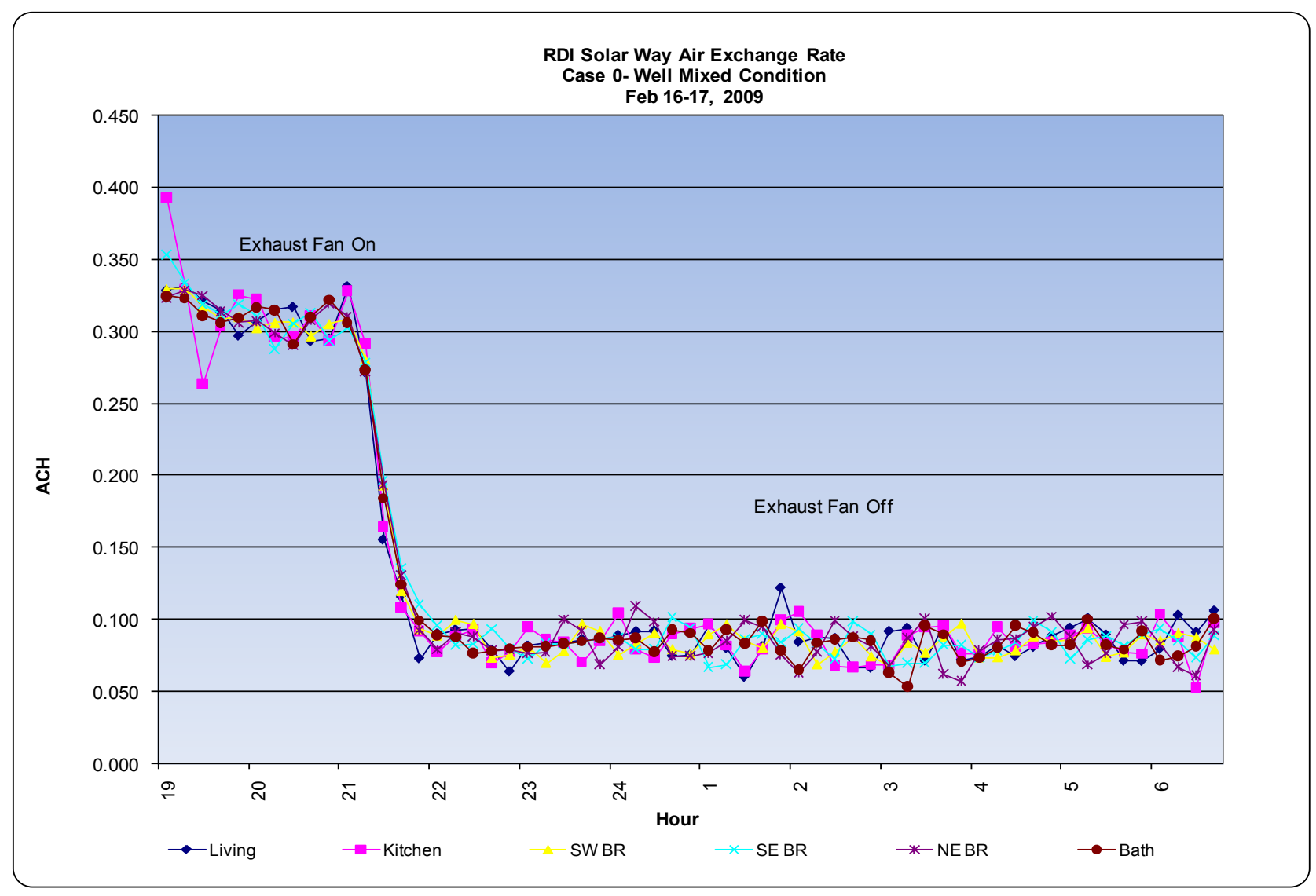

Figure 21. Air exchange rate (case 0 )

\subsection{Conclusions}

The six sampling points (Figure 21) showed very close air exchange rates with and without the exhaust fan running. The combined ventilation rate with the exhaust fan running averages 0.32 $\mathrm{ACH}(64 \mathrm{cfm})$. The natural infiltration rate averages $0.075 \mathrm{ACH}(14 \mathrm{cfm})$ without the central exhaust fan running. This natural infiltration $\mathrm{ACH}$ matches very well with the blower door test results of $0.07 \mathrm{ACH}$ year average Estimated Natural Infiltration Rate (ENIR). This is probably due to the mild wind conditions throughout the Case 0 test period.

\subsection{Age of Air - Concentration Decay Method (Cases 1-4)}

The age of air - concentration decay method (Cases 1 to 4) was used to test room-to-room distribution of outside air. Of particular concern are the second-floor bedrooms where occupants sleep with the doors closed.

Neither space heaters nor room mixing fans were used during Cases 1 to 4 . The tests conducted were under the boundary conditions of nonuniform temperature and no perfect-mixing conditions.

With this in mind, the sampling points' age of air represents only the local-mean age of air (or use RAoA as measurement unit) at the center of the rooms. However, the tests convey enough 
information about the outside air flow distribution throughout the house at different locations. All results and notations hereafter such as "living room" refer to the living room sample point conditions only.

The test begins with injecting a tracer gas (SF6) and mixing it uniformly throughout the home. Then injection and mixing cease and a single gas analyzer with tubing to each sampling point is used to monitor the concentration of the tracer gas as it decays.

Refer to Table 3 for the Tracer gas test matrix. All four cases have the central exhaust fan continuously running. Cases 1 and 2 have the bedroom doors closed, but the distribution/transfer fan was turned on in Case 1 and off in Case 2. Cases 1 and 2 were designed to determine the effect of the distribution/transfer fan. Case 3 was further tested to compare the distribution/transfer fan effect versus controlled outside air openings ( $1 \mathrm{in}^{2}$ through window cracks [Figure 20]) into bedrooms (a leakier house). Case 4 is the same as Case 1 except the bedroom doors were closed. Case 4 was designed to determine the effect of open versus closed bedroom doors under normal operating conditions.

Age of air - concentration decay method tests normally last a few hours. Tests normally end when either the decay curve shape becomes a simple exponential, or the equivalent of $1.5 \mathrm{ACH}$ has occurred. For the Wisdom Way Solar Village test unit, every test case lasted overnight, so overnight temperatures can be measured with relatively stable outside air conditions.

Figure 22 is an example of an enlarged plot of concentration decay of tracer gas for the first six hours of the test period. In all cases, test conditions were sufficiently steady to use the age-of-air method. The first-floor tracer gas concentration decayed faster than that of the second-floor rooms. In the second-floor main bathroom, where the outside air escaped last, the concentration decay rate stayed in the middle range because the exhaust fan kept the air flow rate in the room high. 


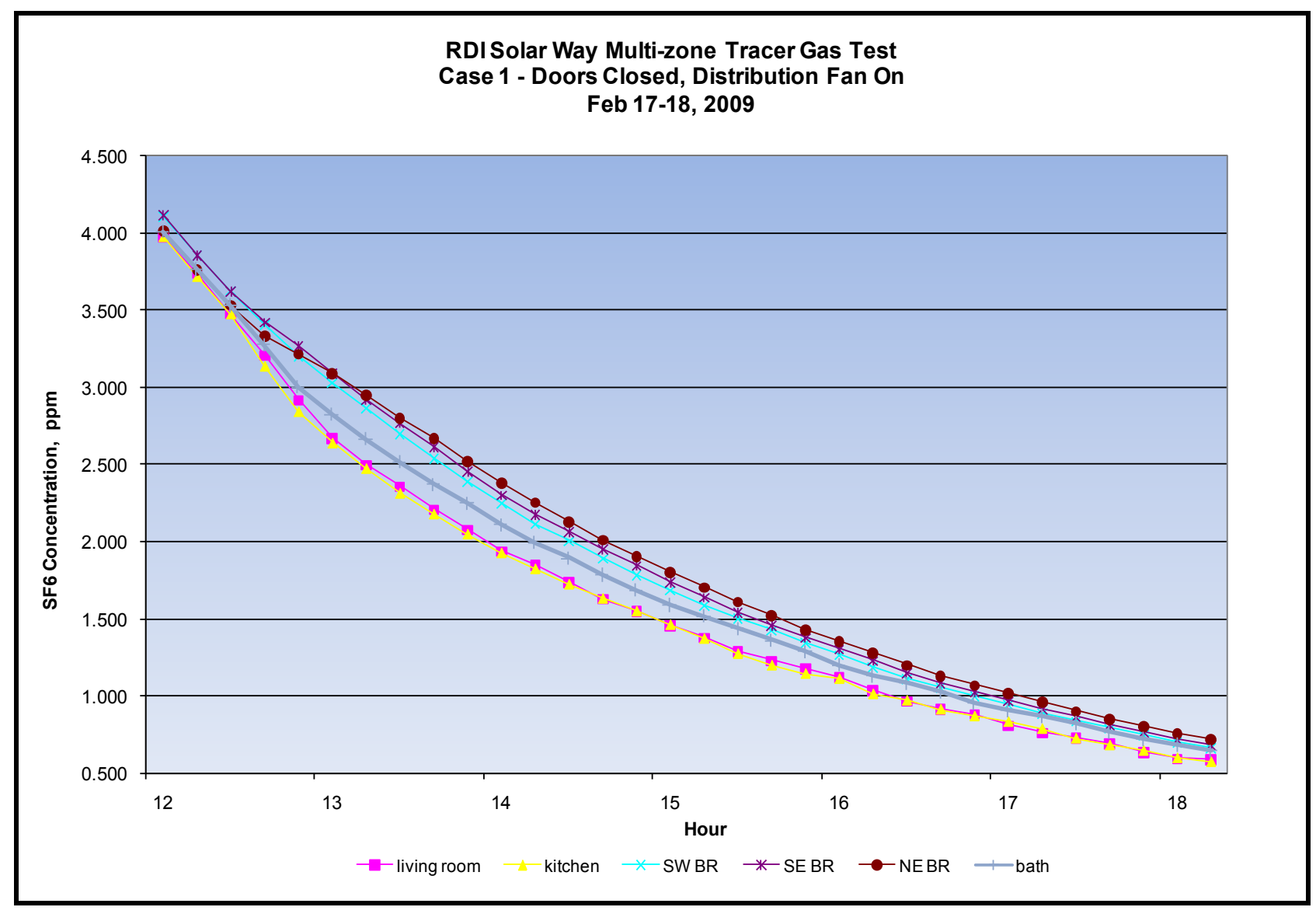

Figure 22. Concentration decay plot (case 1)

Table 6 and Figure 23 summarize the tracer gas test results using RAoA as the metric for comparison.

Table 6. RAoA Summary

\begin{tabular}{|c|c|c|c|c|c|c|c|}
\hline \multirow{3}{*}{$\begin{array}{l}\text { Case } \\
\text { No. }\end{array}$} & \multirow{3}{*}{ Description } & \multicolumn{6}{|c|}{ RAoA } \\
\hline & & $\begin{array}{l}\text { Living } \\
\text { Room }\end{array}$ & Kitchen & SW BR & SE BR & NE BR & Bath \\
\hline & & $\left(h^{-1}\right)$ & $\left(h^{-1}\right)$ & $\left(h^{-1}\right)$ & $\left(h^{-1}\right)$ & $\left(h^{-1}\right)$ & $\left(h^{-1}\right)$ \\
\hline 1 & Distribution fan on, doors closed & 0.324 & 0.317 & 0.293 & 0.286 & 0.271 & 0.296 \\
\hline 2 & Distribution fan off, doors closed & 0.299 & 0.304 & 0.173 & 0.174 & 0.150 & 0.283 \\
\hline 3 & $\begin{array}{l}\text { Distribution fan off, doors closed, } \\
1 \text { in. }^{2} \text { opening in each bedroom }\end{array}$ & 0.262 & 0.265 & 0.211 & 0.173 & 0.215 & 0.247 \\
\hline 4 & Distribution fan on, door open & 0.319 & 0.321 & 0.310 & 0.306 & 0.309 & 0.308 \\
\hline
\end{tabular}




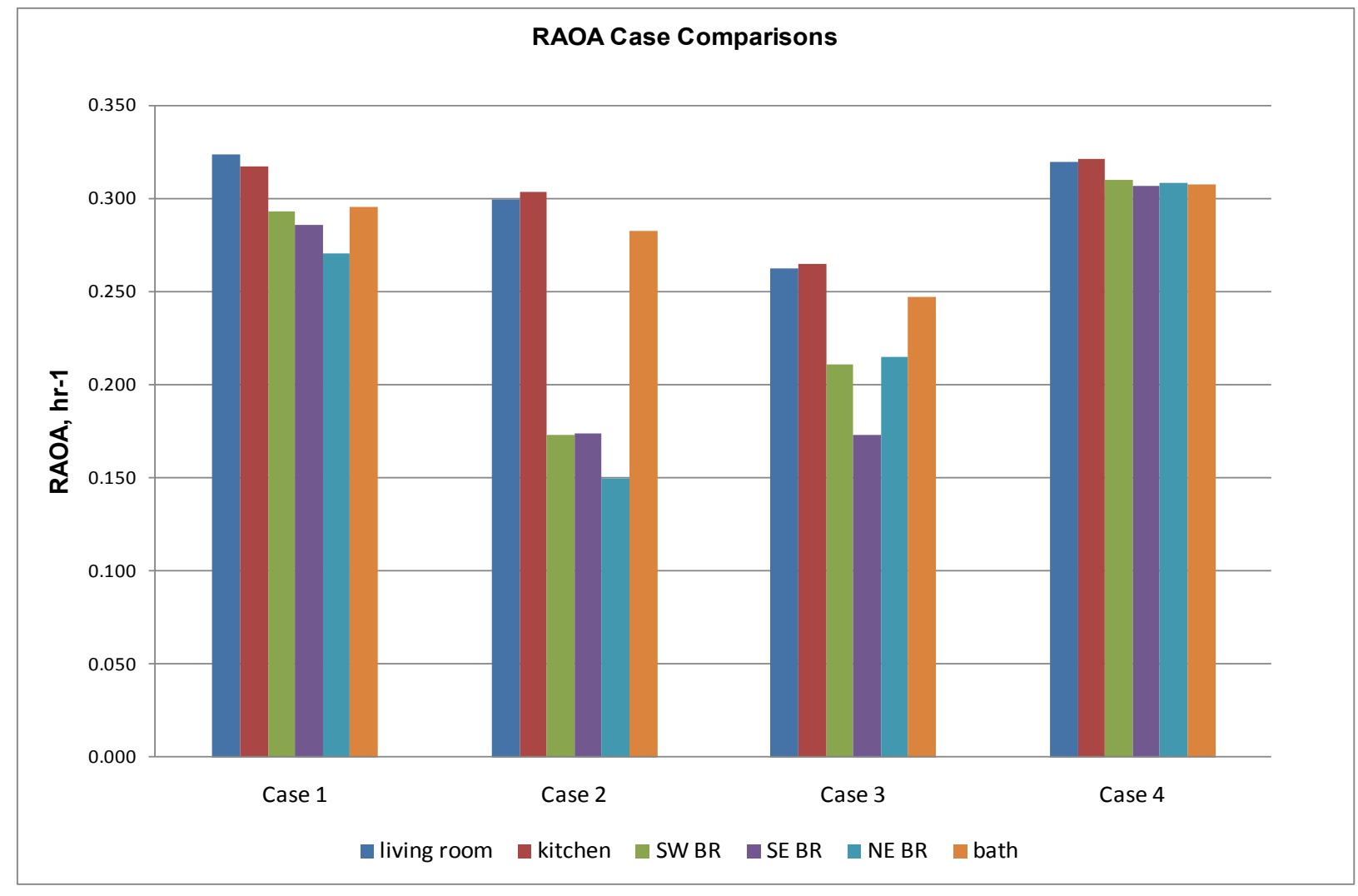

Figure 23. Tracer gas test summary (RAoA)

\subsubsection{Conclusions}

- A distribution/transfer fan effectively distributes outdoor air into second-floor bedrooms. Without this fan, the second-floor bedroom sampling points showed much lower RAoA (the air stays longer in the bedrooms). With the fan, the sampling points RAoA stayed close.

- Occupants will be encouraged to leave unoccupied second-floor bedroom doors open to help distribute outside air by natural stack buoyancy effect.

- One square-inch openings through the window cracks (Figure 20) in each bedroom increased outside air distribution in second-floor bedrooms. But the openings brought in unwanted natural ventilation that suppressed the outside air flow from the first floor to upstairs. This decreased the first-floor RAoA (first-floor outside air took longer to escape). The overall effect is undesirable, so this practice is not recommended. 


\subsection{Room Temperature Measurements}

Each tracer gas test spanned overnight so that overnight room temperatures could be brought to steady conditions. Center-of-room temperatures and outside air temperatures were continuously recorded during the tests.

The Monitor heater sensor is located at the southeast corner of the unit. Space heater temperature set point was maintained at $70^{\circ} \mathrm{F}$, with $\pm 2^{\circ} \mathrm{F}$ of dead band. The sampled room temperatures were in the centers of the rooms.

\subsection{Overnight Temperature Distribution Measurements}

Figure 25 through Figure 28 show the center-of-room temperature distribution plots of Cases 0 , $1,2,4$, and 5 .

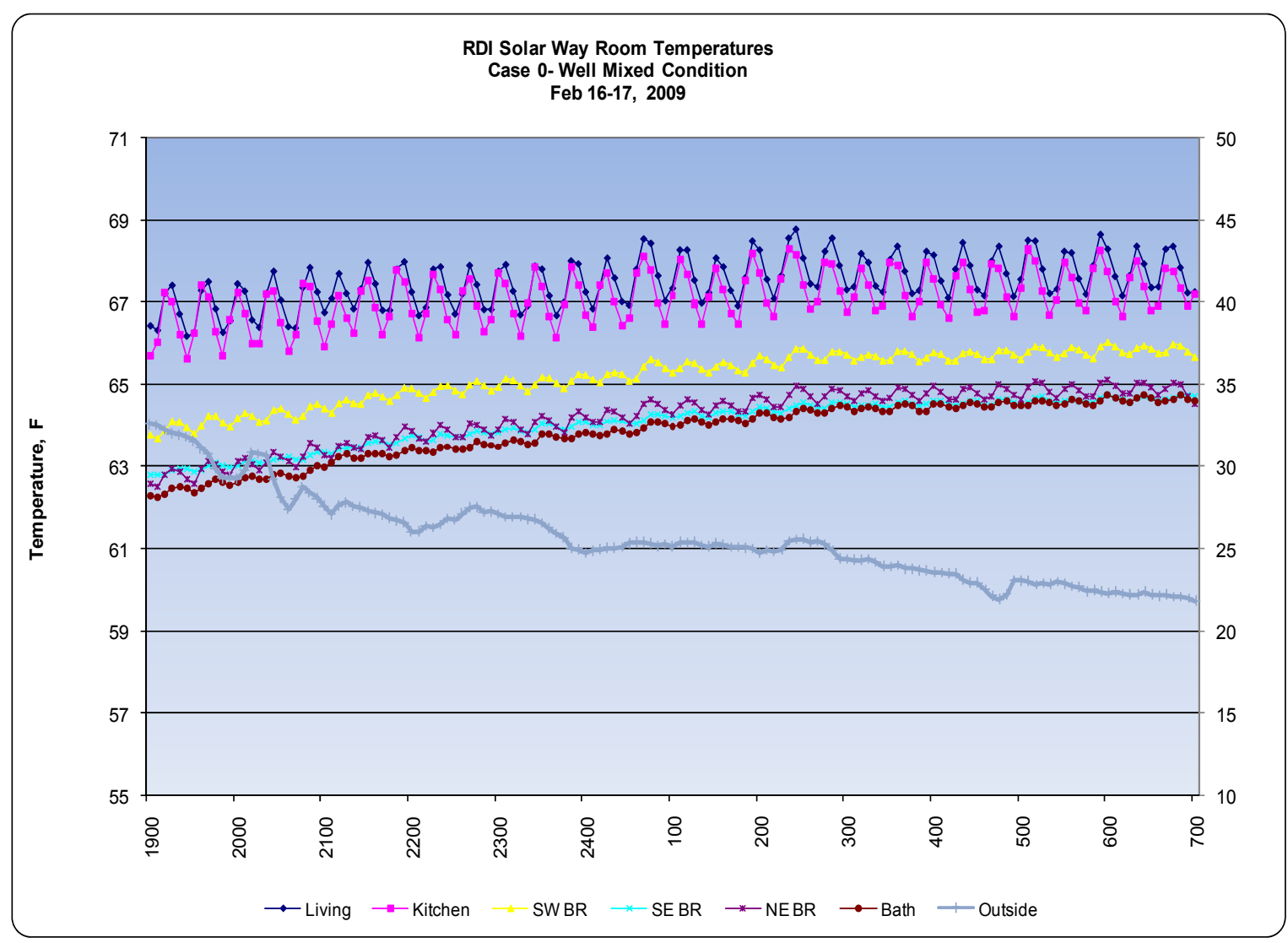

Figure 24. Temperature distribution (Case 0 )

Case 5 was created as the last test metric for temperature distribution. Case 5 is the same as Case 1, except a $60-\mathrm{W}(205 \mathrm{Btu} \cdot \mathrm{h}$, which corresponds to about $0.85 \mathrm{Met})$ light was installed in each bedroom to simulate heat gains from a human body. This number is slightly higher than the sleeping metabolic rate $(0.7 \mathrm{Met})$, so the room temperature could be slightly lower. 
Case 3 temperature measurements were not taken because 1 -in. ${ }^{2}$ openings brought unwanted cold air into the space and made the bedrooms even colder. Room temperatures are plotted on the primary axis; outside air temperatures on the secondary axis.

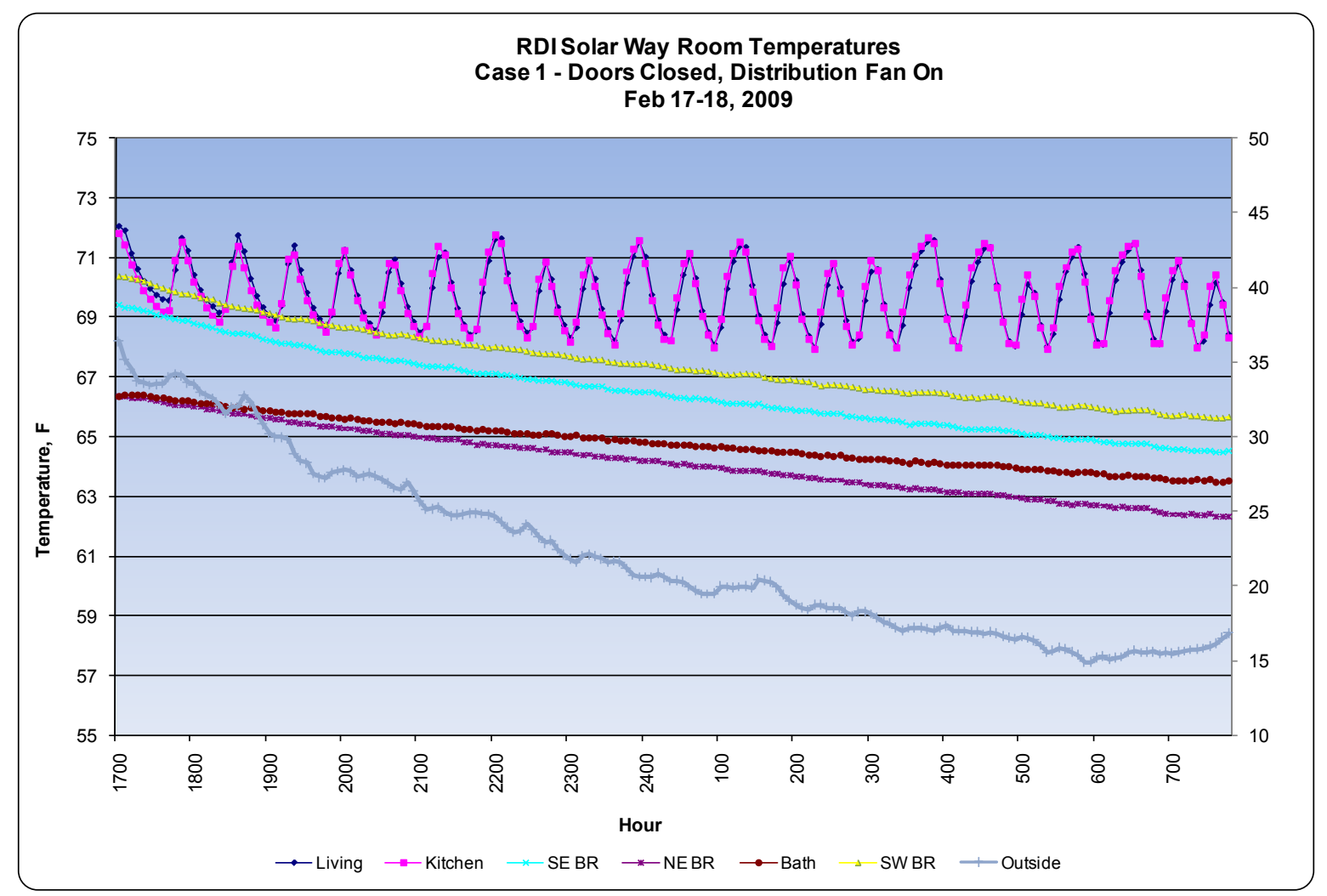

Figure 25. Temperature distribution overnight plot (Case 1) 


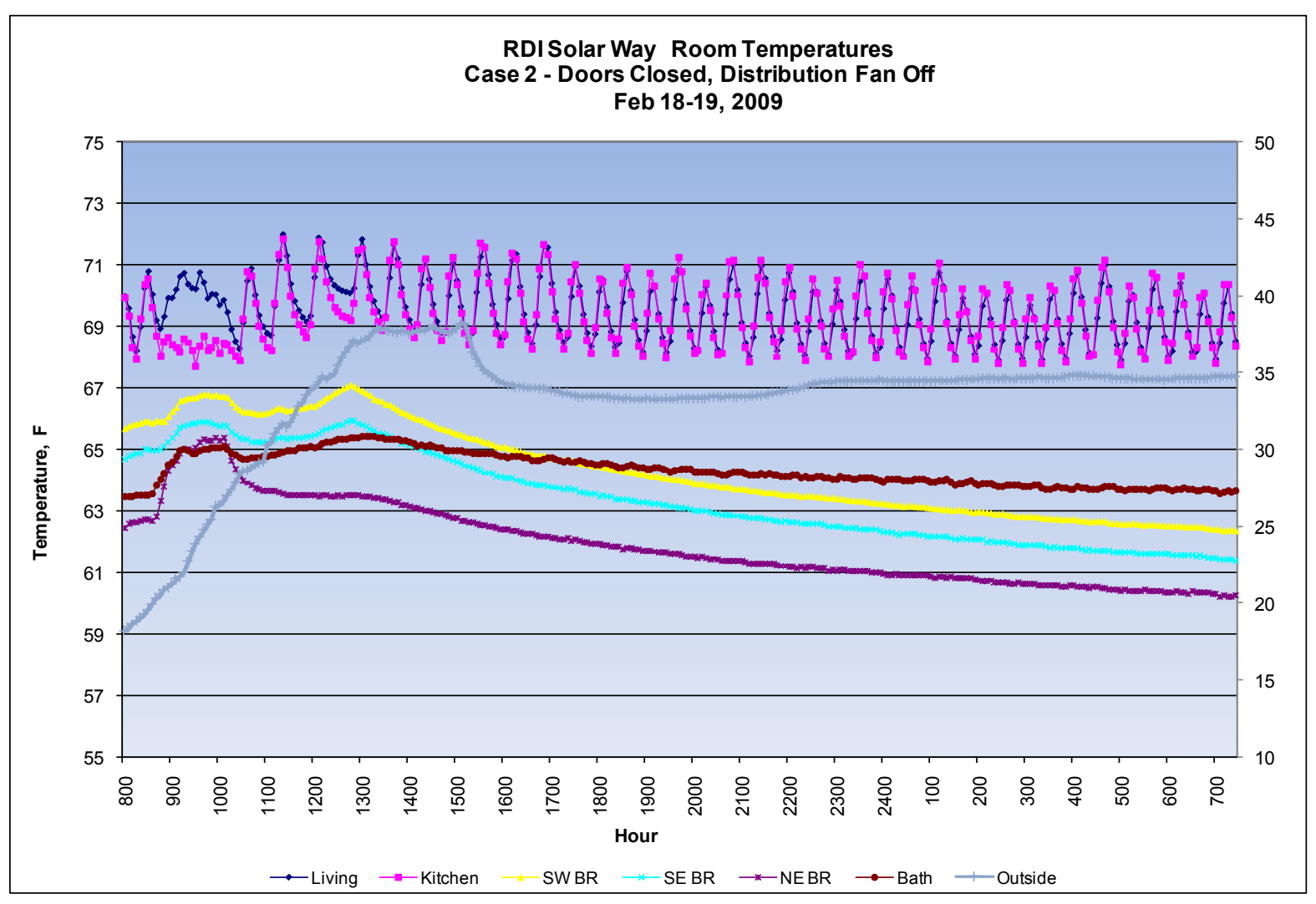

Figure 26. Temperature distribution overnight plot (Case 2) 


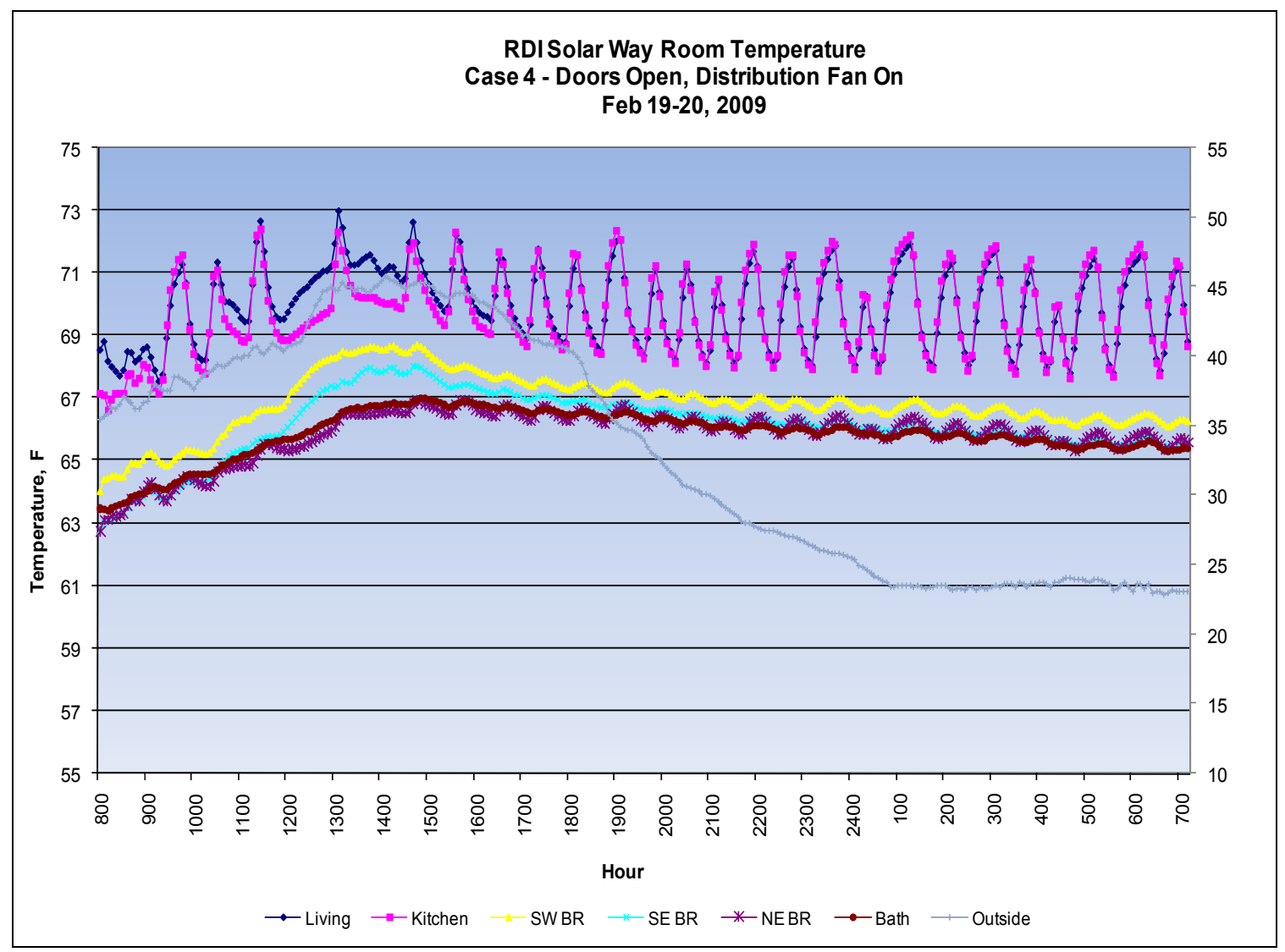

Figure 27. Temperature distribution overnight plot (Case 4) 


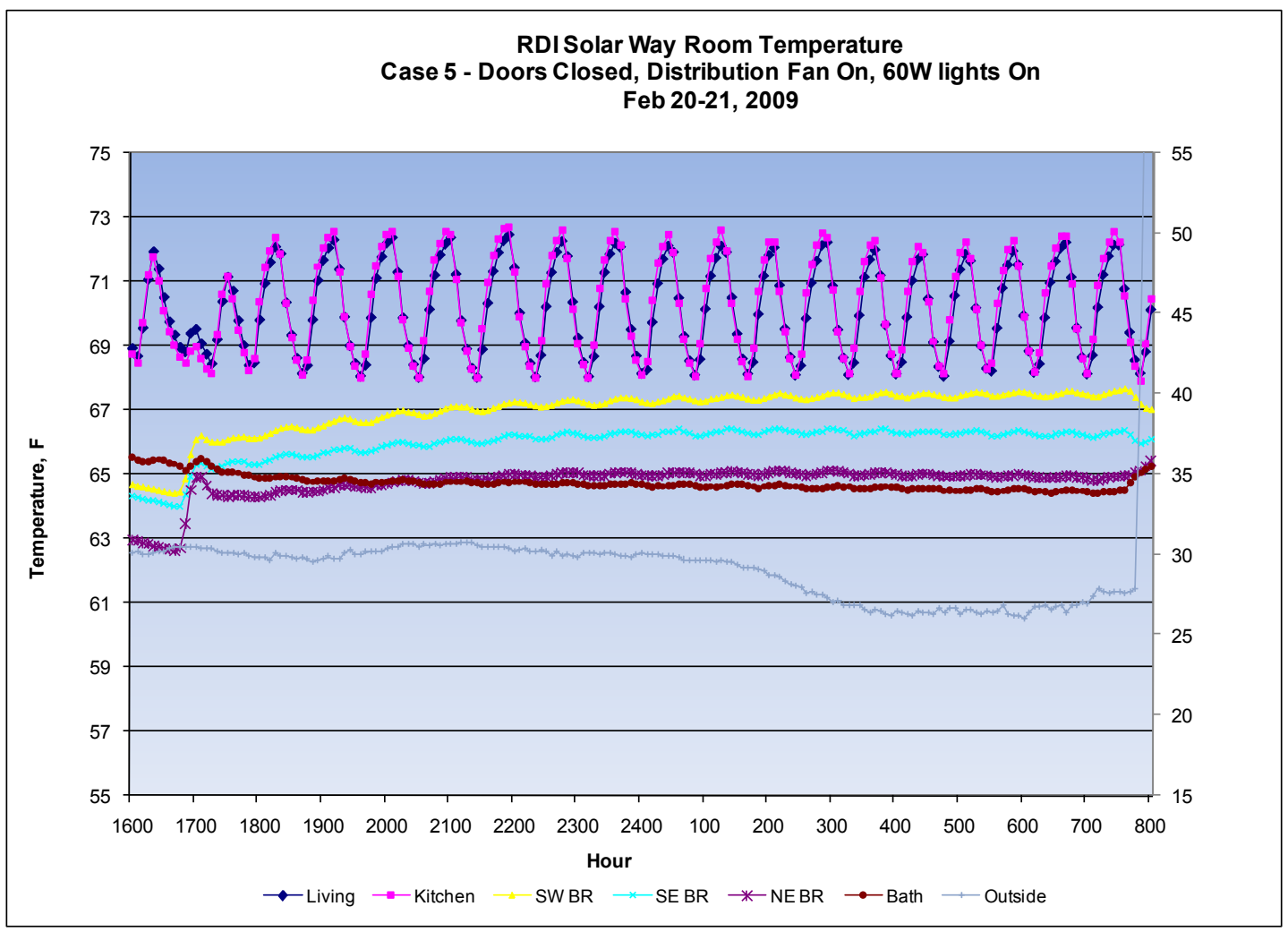

Figure 28. Temperature distribution overnight plot (Case 5)

We made the following observations:

- Case 1 experienced the lowest outside air temperature $\left(14.92^{\circ} \mathrm{F}\right)$ for a short time. Compared to ASHRAE heating design $2^{\circ} \mathrm{F}$, this outdoor condition was relatively mild. Cases 2,4 , and 5 outside temperatures were all mild $\left(20^{\circ}-35^{\circ} \mathrm{F}\right)$.

- First-floor kitchen and living room sampling point temperatures stayed very close throughout the nights. During the midmornings and early afternoons, the south-facing living room warmed from solar heat gains.

- Under well-mixed conditions (Case 0), the sampled living room temperature stayed slightly cooler $\left(67^{\circ} \mathrm{F}\right)$ than the set point. The interzonal mixing fan continously mixed second-floor air with first-floor air and cooled the first floor air. For the other cases, the sampled living room temperatures stayed close to the heater set point $\left(70^{\circ} \mathrm{F}\right)$ with $\pm 2^{\circ} \mathrm{F}$ dead band.

- Leaving the bedroom doors open (Case 4) helps to reduce the room-to-room temperature difference.

- Operating the distribution/transfer fan (Cases 1 and 4 [Figure 27 and Figure 28]) helps to reduce room-to-room temperature difference. When Case 1 experienced the coldest outside air conditions, the upstairs bedrooms remained near $60^{\circ} \mathrm{F}$. 
- In all cases, the upstairs remained about $4^{\circ}-7^{\circ} \mathrm{F}$ degrees cooler than the downstairs, varying from case to case.

- In all cases, the upstairs bedrooms had about $1^{\circ}-2^{\circ} \mathrm{F}$ difference, varying from case to case. The southwest bedroom showed consistently higher temperatures (about $1^{\circ}-2^{\circ} \mathrm{F}$, varying from case to case) than the other two bedrooms because its southwest exposure had high solar heat gains.

\subsection{Thermal Imaging Test (Infrared Camera)}

Infrared pictures were taken to measure noticeable hot and cold spots on interior surfaces. There was normal infiltration through the wall sill plate and foundation and window and door frames. Overall, the test unit showed a consistently high insulation level.

Figure 29 through Figure 36 show thermal imaging for various places in the building. Figure 33 shows cold spots at the attic access door edge under normal operating conditions when warm air escaped. A better air seal gasket is recommended for the attic access door.

We measured surface temperature for the following surfaces during the midmorning of February 17. (To avoid disturbing the ongoing tracer gas test, we did not measure any surface temperatures in the upstairs bedrooms.)

- Living room

○ South wall: $71.5^{\circ} \mathrm{F}$

○ East wall: $72^{\circ} \mathrm{F}$

○ West wall: $71^{\circ} \mathrm{F}$

○ North wall: $68^{\circ} \mathrm{F}$

o Floor: $69^{\circ} \mathrm{F}$

○ Ceiling: $70.5^{\circ} \mathrm{F}$

○ Air temperature: $73^{\circ} \mathrm{F}$

- Second floor

○ Ceiling: $67^{\circ} \mathrm{F}$

○ Stairway north wall: $67^{\circ} \mathrm{F}$. 

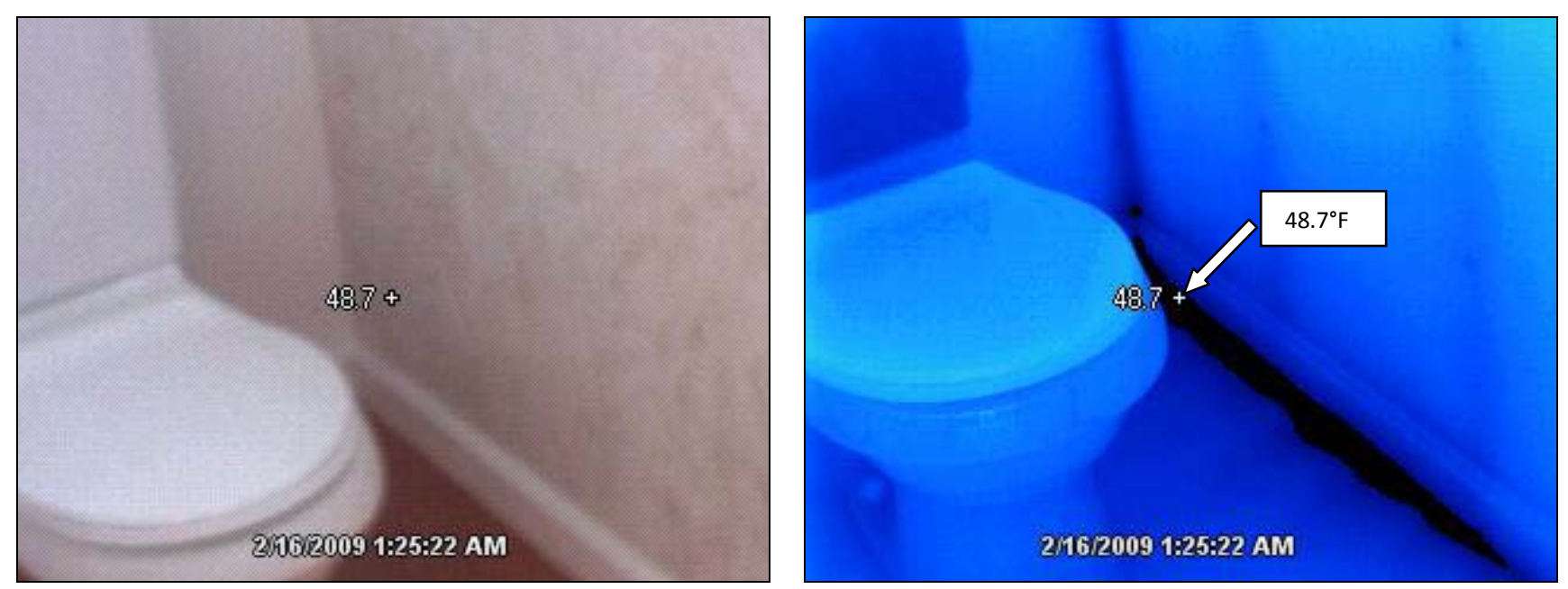

Figure 29. First-floor bathroom north corner thermal imaging
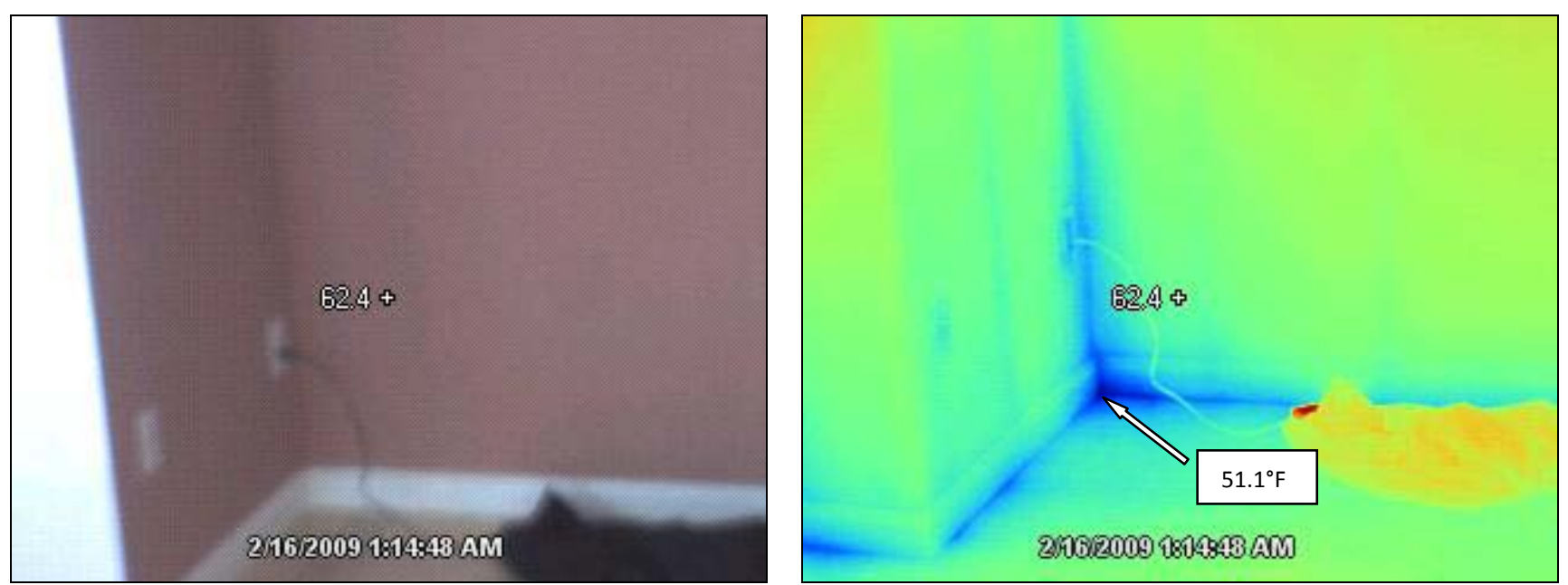

Figure 30. Living room southwest corner thermal imaging
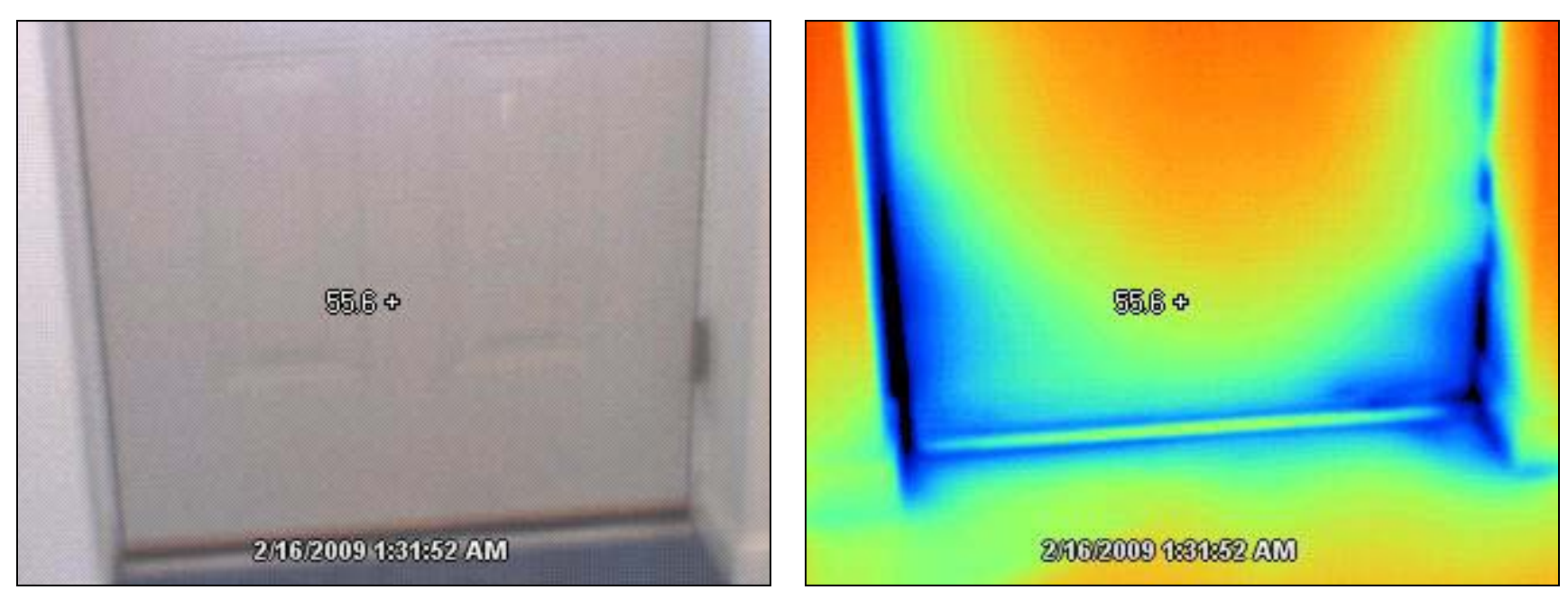

Figure 31. First-floor north entry door thermal imaging 


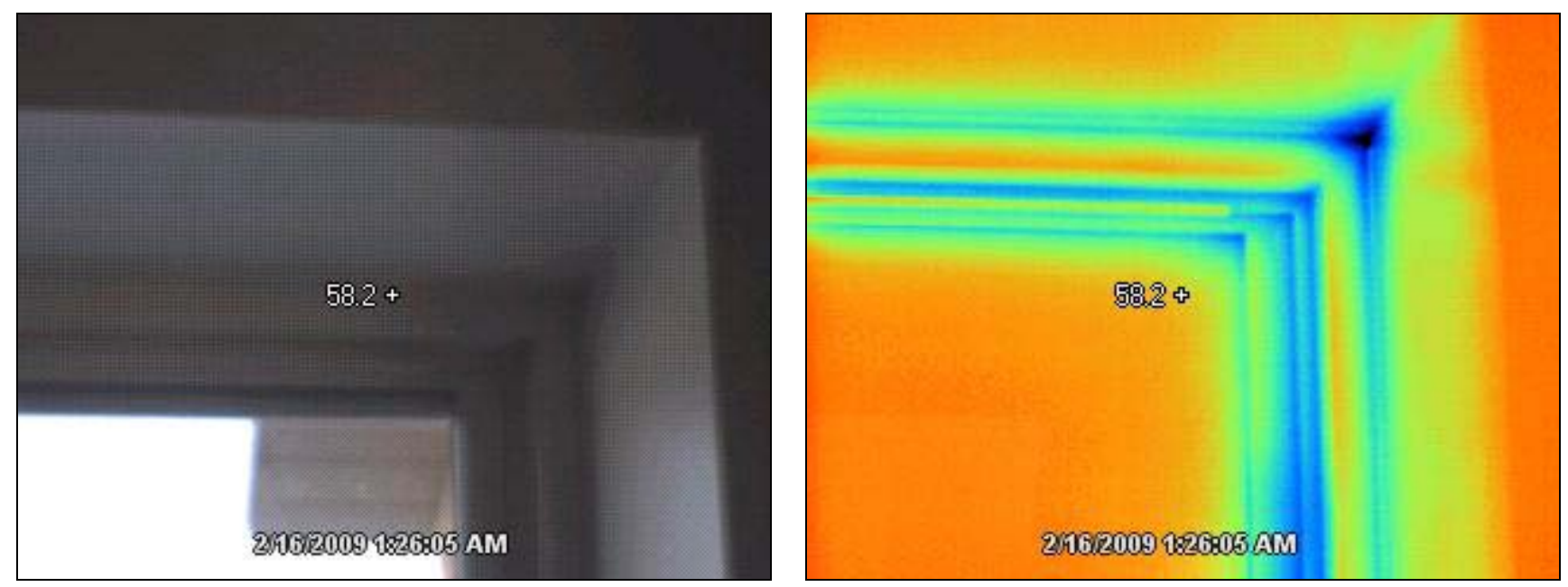

Figure 32. First-floor east window framing thermal imaging
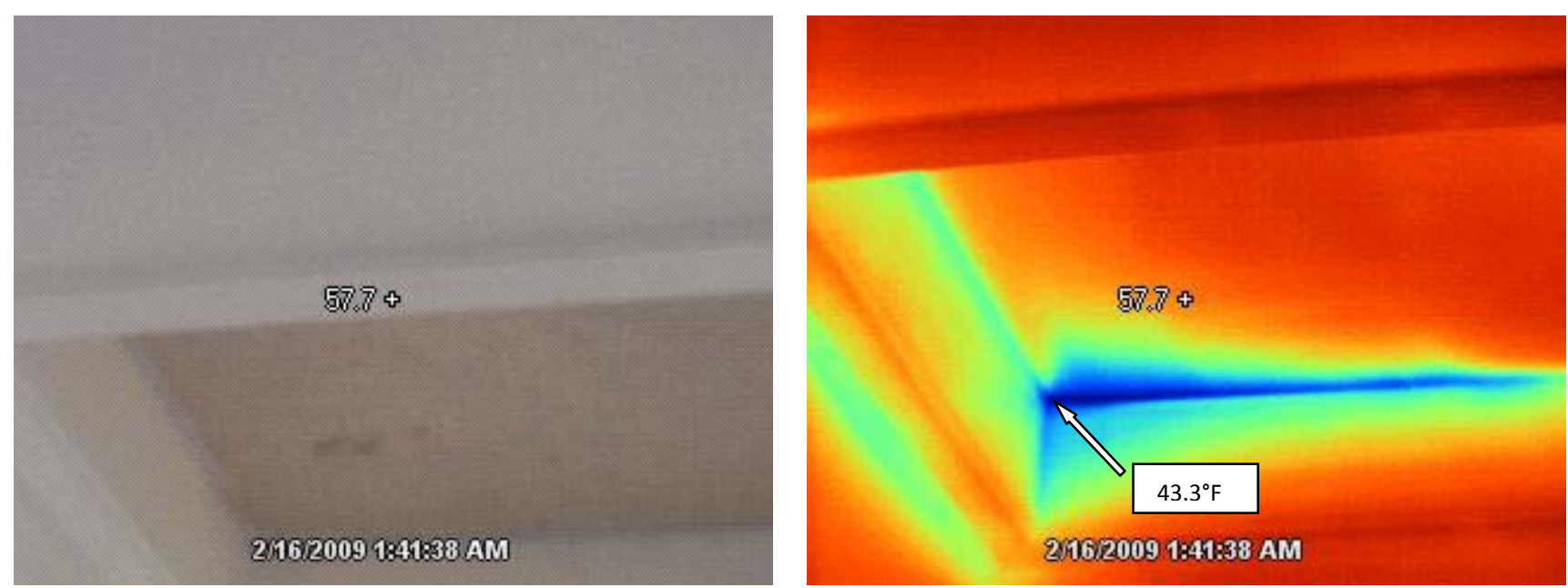

Figure 33. Attic access door thermal imaging
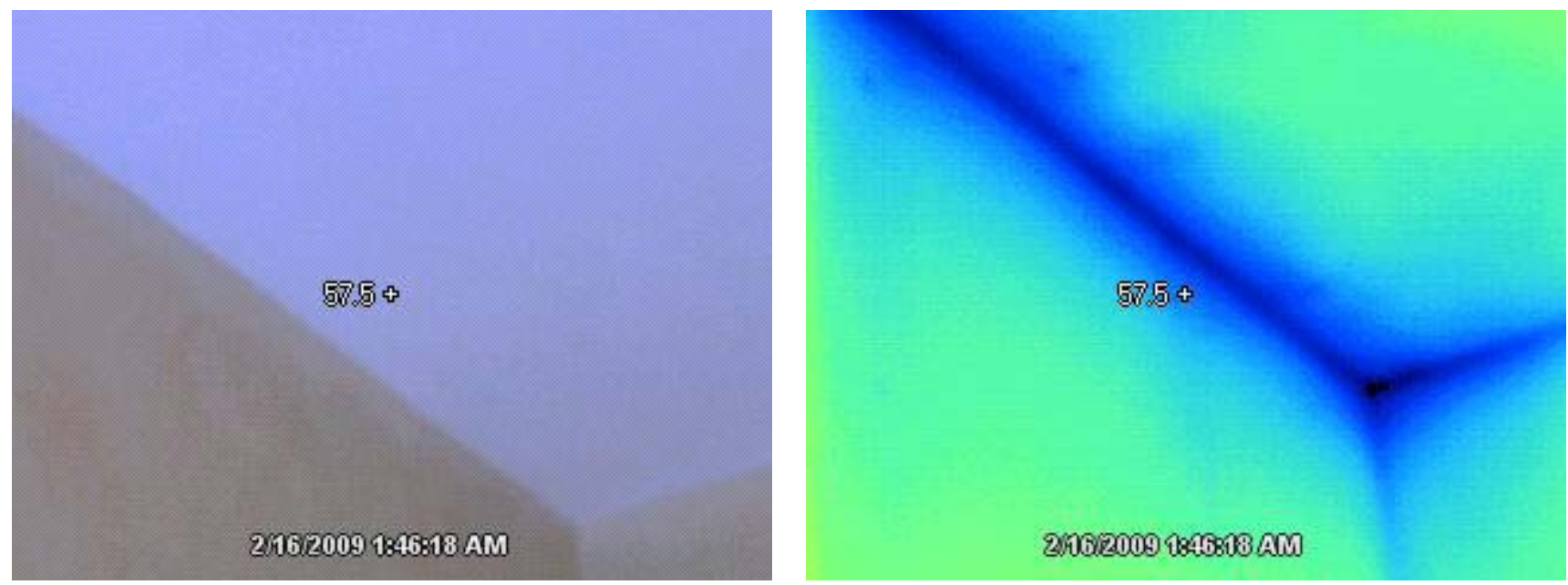

Figure 34. Southwest bedroom ceiling thermal imaging 

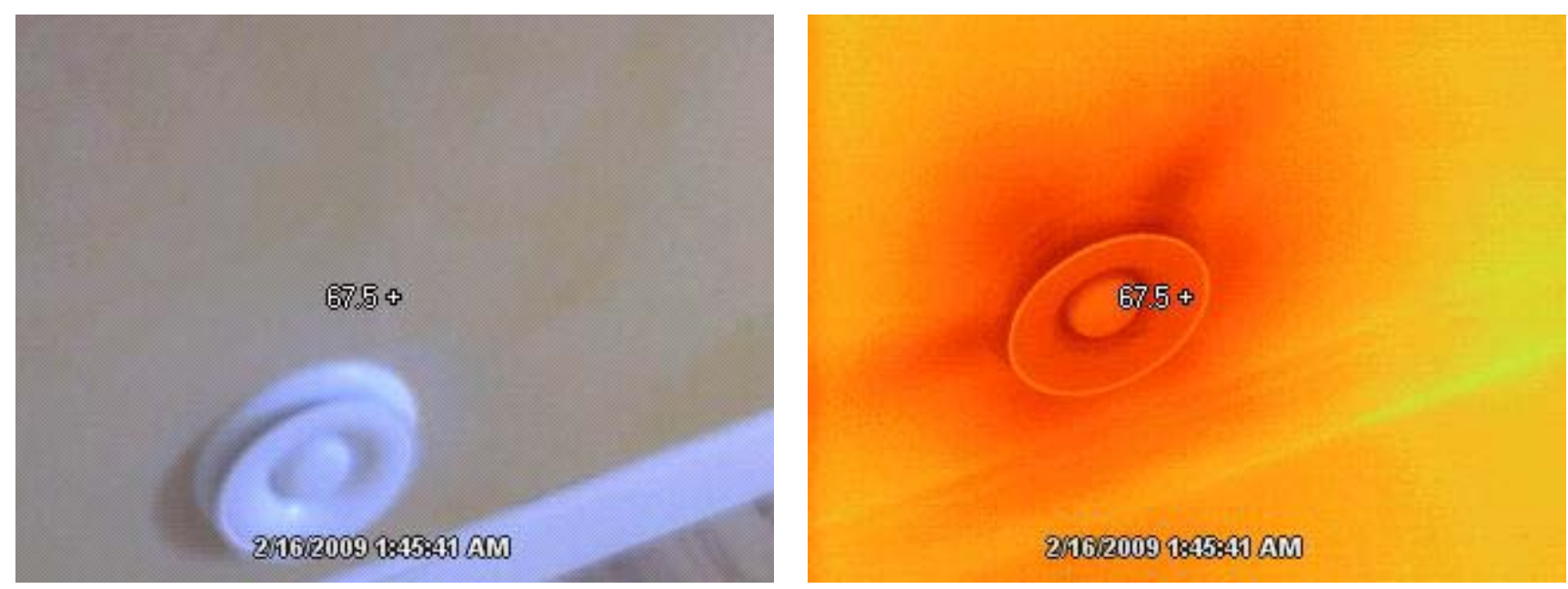

Figure 35. Southeast bedroom distribution diffuser thermal imaging
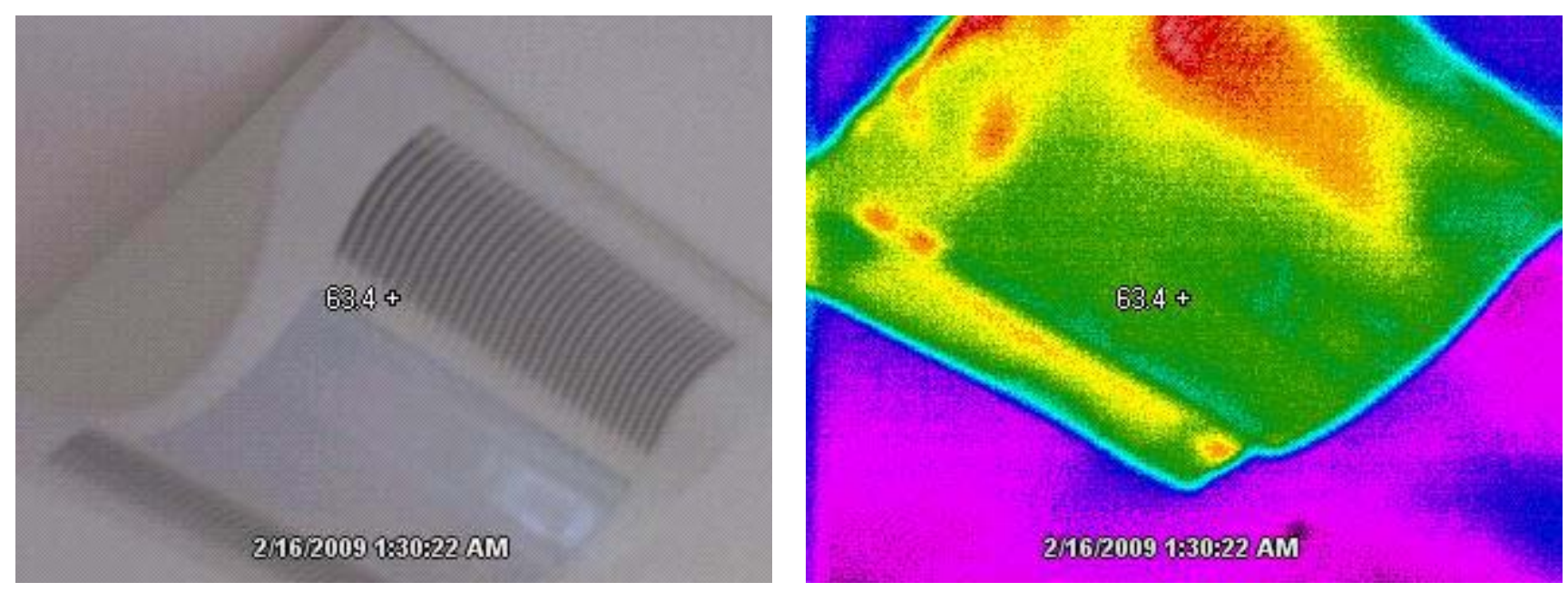

Figure 36. Central exhaust fan thermal imaging

\subsection{Indoor Air Temperature Distribution Evaluation}

Research question Q.11 is targeted at indoor air temperature and thermal comfort:

Q.11.What are the temperatures in various rooms throughout the duplex over consecutive 24hour periods with each condition shown in Table 4? Does a central point in each room meet the ASHRAE Standard 55 comfort recommendations at various times during each test? Are there any noticeable hot or cold spots on interior surfaces as measured using an IR camera? Do temperature differentials between rooms meet ACCA Manual RS guidelines $\left(4^{\circ} \mathrm{F}\right.$ maximum)?

The following sections will evaluate the system according to the ACCA Manual RS guideline, ASHRAE standard 55 with thermal comfort simple analysis, and an occupant survey. 


\subsubsection{ACCA Manual RS Guideline Reference}

Table 7 shows temperature instantaneous recordings at 6:00 a.m. near the end of the test period in February 2009. Case 5 (doors closed, transfer fan on, and $60 \mathrm{~W}$ simulating human body heat gain) is closest to normal operating conditions.

Table 7. Instantaneous Temperature Recordings at 6:00 a.m.

\begin{tabular}{|l|c|c|c|c|c|c|}
\hline & \multirow{2}{*}{ Unit } & Case 0 & Case 1 & Case 2 & Case 4 & Case 5 \\
\cline { 3 - 7 } & & $\mathbf{2 / 1 7 / 0 9}$ & $\mathbf{2 / 1 8 / 0 9}$ & $\mathbf{2 / 1 9 / 0 9}$ & $\mathbf{2 / 2 0 / 0 9}$ & $\mathbf{2 / 2 1 / 0 9}$ \\
\hline Living Room Temperature & ${ }^{\circ} \mathrm{F}$ & 68.28 & 68.18 & 68.04 & 71.28 & 69.94 \\
\hline Kitchen Temperature & ${ }^{\circ} \mathrm{F}$ & 67.77 & 68.07 & 67.87 & 71.60 & 69.91 \\
\hline Southwest Bedroom Temperature & ${ }^{\circ} \mathrm{F}$ & 66.02 & 65.95 & 62.53 & 66.34 & 67.57 \\
\hline Southeast Bedroom Temperature & ${ }^{\circ} \mathrm{F}$ & 64.76 & 64.85 & 61.59 & 65.59 & 66.33 \\
\hline Northeast Bedroom Temperature & ${ }^{\circ} \mathrm{F}$ & 65.12 & 62.69 & 60.35 & 65.79 & 64.99 \\
\hline Bathroom Temperature & ${ }^{\circ} \mathrm{F}$ & 64.76 & 63.73 & 63.70 & 65.44 & 64.54 \\
\hline Basement Temperature & ${ }^{\circ} \mathrm{F}$ & 43.51 & 44.39 & 44.62 & 44.53 & 44.67 \\
\hline Outside Air Temperature & ${ }^{\circ} \mathrm{F}$ & 22.29 & 15.19 & 34.59 & 23.11 & 26.06 \\
\hline Wind Speed & ${ }^{\mathrm{m}} / \mathrm{s}$ & 0.20 & 0.20 & 0.20 & 0.81 & 0.20 \\
\hline \hline Maximum Room Temperature & ${ }^{\circ} \mathrm{F}$ & 68.29 & 68.18 & 68.04 & 71.60 & 69.94 \\
\hline Minimum Room Temperature & ${ }^{\circ} \mathrm{F}$ & 64.76 & 62.69 & 60.35 & 65.59 & 64.99 \\
\hline Maximum Room to Room $\Delta \mathbf{T}$ & ${ }^{\circ} \mathrm{F}$ & 3.53 & 5.49 & 7.69 & 6.01 & 4.95 \\
\hline Average Floor to Floor $\boldsymbol{\Delta} \mathbf{T}$ & ${ }^{\circ} \mathrm{F}$ & 2.86 & 3.82 & 5.91 & 5.65 & 4.07 \\
\hline
\end{tabular}

The maximum temperature (occurring in the living room) is $69.94^{\circ} \mathrm{F}$. The minimum room temperature (occurring in the northeast bedroom) is $64.99^{\circ} \mathrm{F}$. A maximum $\Delta \mathrm{T}$ between rooms is $5^{\circ} \mathrm{F}$. It is greater than ACCA Manual RS guidelines of $4^{\circ} \mathrm{F}$ maximum.

Case 1 simulates no human body heat gain, and Case 1 experienced the coldest outside air temperature $\left(15.19^{\circ} \mathrm{F}\right)$ at $6: 00 \mathrm{a} . \mathrm{m}$. The northeast bedroom temperature dropped to $62.69^{\circ} \mathrm{F}$; the maximum room-to-room $\Delta \mathrm{T}$ was $5.49^{\circ} \mathrm{F}$. Under extreme winter weather conditions, the northeast bedroom room temperature may drop below $60^{\circ} \mathrm{F}$.

In Cases 1 and 5, the average temperatures between the upstairs and downstairs are very close to $4^{\circ} \mathrm{F}\left(3.82^{\circ} \mathrm{F}\right.$ Case $1 ; 4.07^{\circ} \mathrm{F}$ Case 5$)$.

According to ACCA Manual RS, the design deviates from the $4^{\circ} \mathrm{F}$ rule. Of particular concern is the northeast bedroom.

\subsubsection{ASHRAE Standard 55 Reference}

ASHRAE standard 55 has comprehensive guidelines for thermal comfort validations. The current measurement variables are too incomplete to validate the model. 
A simple analysis tool (PMVcalc) is used with the following parameters as a rough estimate. For future field tests, comfort meters will be used for verification.

The northeast bedroom was selected for calculation. The outdoor air temperature used is $16^{\circ} \mathrm{F}$ with indoor air temperature at $62^{\circ} \mathrm{F}$, derived from test conditions. A relatively simple room mean radiant temperature calculation was performed counting all wall, ceiling, floor, and window surfaces. On cold winter nights, the room occupant will feel cool (PMV -2.2) with a clothing level of 2 when the room temperature is kept at $62^{\circ} \mathrm{F}$, estimating mean radiant temperature of $61.5^{\circ} \mathrm{F}$. For a highly insulated envelope, the room's mean radiant temperature is much closer to room temperature than a conventional house envelope (see Figure 37 and Figure 38).

\begin{tabular}{|c|c|}
\hline Parameter & Input \\
\hline Clothing (clo) & 2.00 \\
\hline Air temp. $\left({ }^{\circ} \mathrm{C}\right)$ & 16.7 \\
\hline Mean radiant temp. $\left({ }^{\circ} \mathrm{C}\right)$ & 16.4 \\
\hline Activity (met) & 0.7 \\
\hline Air speed $(\mathrm{m} / \mathrm{s})$ & 0.10 \\
\hline Relative humidity (\%) & 30.0 \\
\hline \multicolumn{2}{|c|}{ Calculate PMV } \\
\hline Parameter & Results \\
\hline Operative temp. $\left({ }^{\circ} \mathrm{C}\right)$ & 16.55 \\
\hline PMV & -2.2 \\
\hline PPD & 84.9 \\
\hline
\end{tabular}

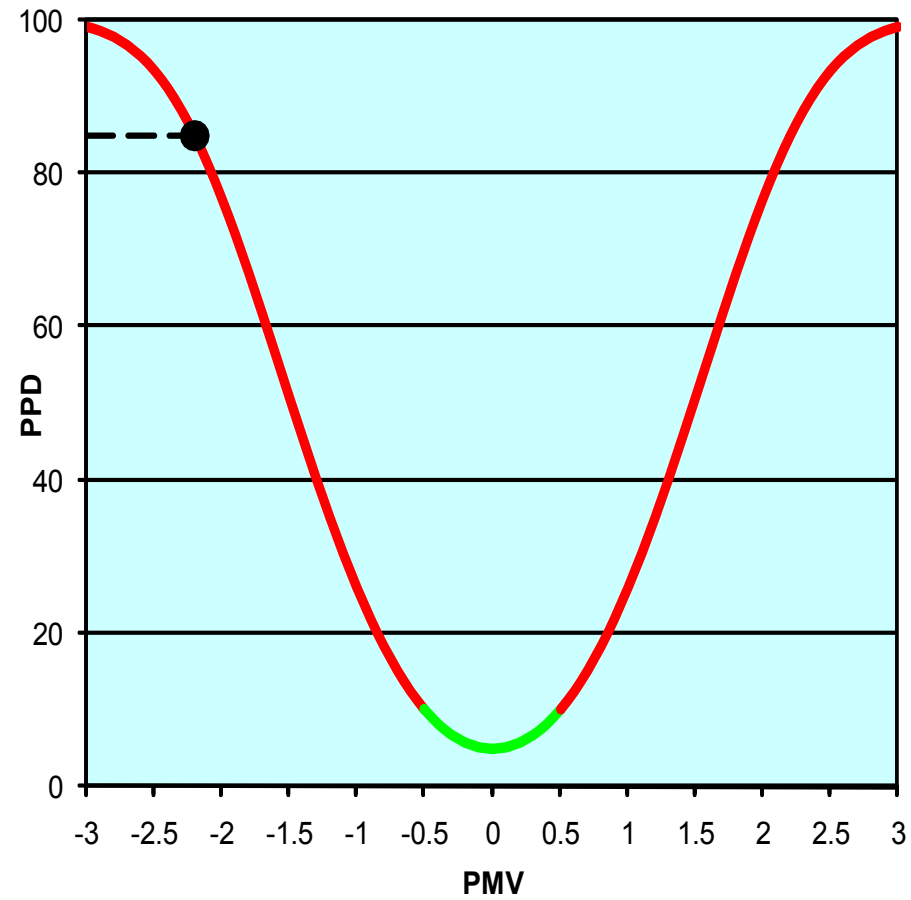

Figure 37. Northeast bedroom comfort estimate (occupant sleeping)

PPD - percent of people dissatisfied; PMV - predicted mean vote

On cold winter days, room occupants will feel cool (PMV -1.9) with a clothing level of 1 when the room temperature is kept at $62^{\circ} \mathrm{F}$, estimating a mean radiant temperature of $61.5^{\circ} \mathrm{F}$. 


\begin{tabular}{|c|c|}
\hline Parameter & Input \\
\hline Clothing (clo) & 1.00 \\
\hline Air temp. $\left({ }^{\circ} \mathrm{C}\right)$ & 16.7 \\
\hline Mean radiant temp. $\left({ }^{\circ} \mathrm{C}\right)$ & 16.4 \\
\hline Activity (met) & 1.0 \\
\hline Air speed $(\mathrm{m} / \mathrm{s})$ & 0.10 \\
\hline Relative humidity (\%) & 30.0 \\
\hline \\
\hline Parameter & Results \\
\hline Operative temp. $\left({ }^{\circ} \mathrm{C}\right)$ & 16.55 \\
\hline PMV & -1.9 \\
\hline PPD & 72.1 \\
\hline
\end{tabular}

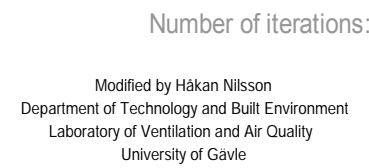

Number of iterations: University of Gave

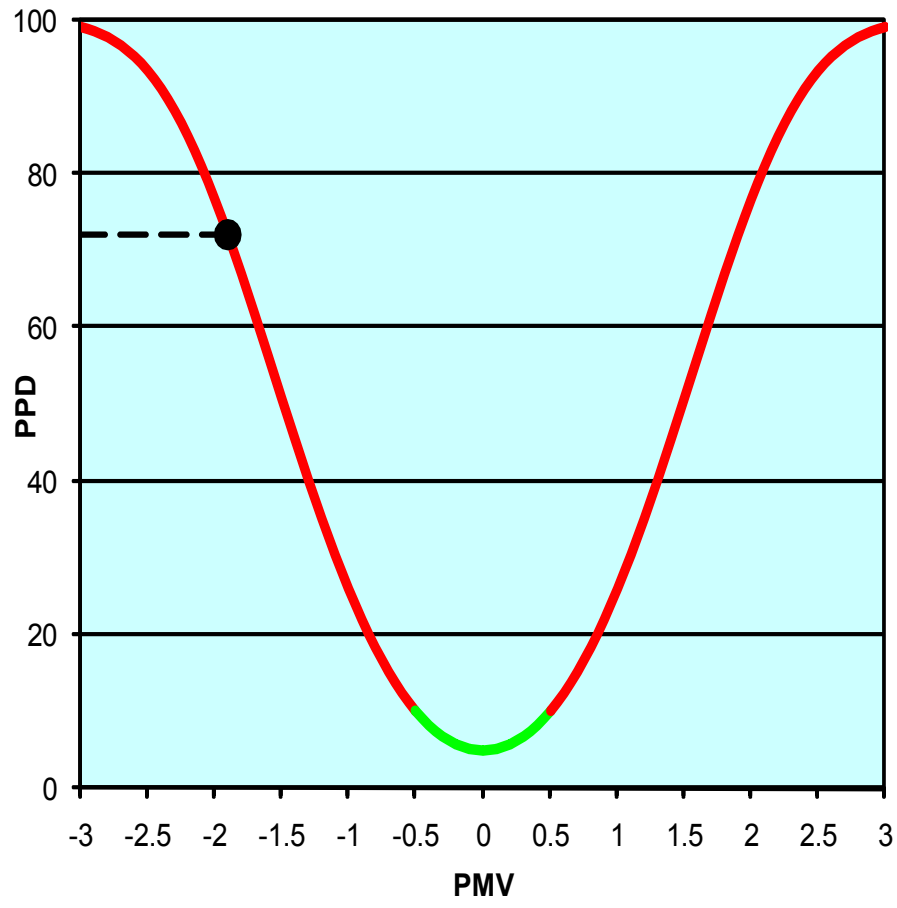

Figure 38. Northeast bedroom comfort estimate (occupant seated)

According to ASHRAE standard 55, upstairs bedrooms, particularly the northeast bedroom, will feel cool during chilly winter days or nights.

Under extreme winter conditions, homeowners are likely to increase the space temperature set point to $72^{\circ}-73^{\circ} \mathrm{F}$ to heat the upstairs. We also recommend that homeowners leave the room doors open during the daytime when the unit is not occupied.

\subsubsection{Occupant Survey (Informal Conversation)}

Robb Aldrich met with the owner of the two-bedroom unit. Aldrich noted the following in an email correspondence:

He leaves his thermostat at $60^{\circ} \mathrm{F}$. "Sometimes," he said, "when I come home, I'll put it up to $62^{\circ}$." So he likes it cool, which is probably why folks that have visited him were a bit concerned. One other interesting note he volunteered: his teenage son seems comfortable in his room with the door closed (with computer, stereo, etc. running) and hasn't wanted to turn up the heat.

When the downstairs thermostat is set to $62^{\circ} \mathrm{F}$, the upstairs bedroom temperature can decrease to $55^{\circ}-58^{\circ} \mathrm{F}$ unless the bedroom has lot of electronic equipment.

This design seems to work well for these homeowners. The question remains: Does it work for the homeowners in general? 


\subsubsection{Conclusions}

CARB's low-cost design approach for Wisdom Way Solar Village traded the cost of a distributed space heating system toward highly insulated envelopes. A point source heating scheme is installed without supplemental heating backup.

Field measurements and analysis showed the space conditions had some deviations from ACCA Manual RS design standards and ASHRAE 55 comfort standards, even though the next door homeowner likes cool spaces. When CARB met with the homeowners, the decision was made that homeowners can install 200 - to $300-\mathrm{W}$ space heaters to closely control room temperatures and bring thermal comfort within neutral range.

Because Building America is targeted toward the broad outreach of general homeowner groups, this design approach is not deemed a complete success without supplemental heating backup.

We recommend that for multistory housing units in cold climates, even with highly insulated envelope construction, small supplemental space heaters are needed for a single-zone point source heating scheme. Our study and conclusion are derived from this project only. 


\subsection{Miscellaneous Tests}

\subsection{Noise Test of the Distribution Fan}

Coldham \& Hartman Architects conducted a noise test of the distribution/transfer fan. There were concerns about the noise the fan generated and about the noise transmission from the first floor to the bedrooms that would be created by opening a separate transmission/distribution path.

A vacuum and a hair dryer were brought into the living room space. The test set the vacuum to low speed, high speed, and high speed with hair dryer on. In each setting, the distribution/transfer fan was first left on with the bedroom doors open and then closed. The distribution/transfer fan was then turned off with the supply duct opening blanket off and the bedroom doors closed. Table 8 shows the decibel (DB) level recordings of the system.

Table 8. Distribution Fan Noise Rating Test

\begin{tabular}{|l|c|c|c|}
\hline \multicolumn{1}{|c|}{ Description } & $\begin{array}{c}\text { Vacuum Low } \\
\text { Speed }\end{array}$ & $\begin{array}{c}\text { Vacuum High } \\
\text { Speed }\end{array}$ & $\begin{array}{c}\text { Vacuum High Speed } \\
\text { With Hair Dryer }\end{array}$ \\
\cline { 2 - 4 } & (DB) & (DB) & (DB) \\
\hline Source & 57 & 64.5 & 80 \\
\hline Open Bedroom Door, Fan On & 36 & 44 & 56 \\
\hline Closed Bedroom Door, Fan On & 34 & 36.5 & 47 \\
\hline Blocked Duct, Fan Off & 29 & 33 & 46.5 \\
\hline
\end{tabular}

The vacuum and the hairdryer were then turned off so no source noise was generated. The recorded sound level was $34.5 \mathrm{DB}$ with the distribution fan on. The recorded sound level was 26.5 DB with the distribution fan turned off.

This test showed that the WhisperGreen transfer fan was quiet and that the noise transmission from the first floor was not a problem. 


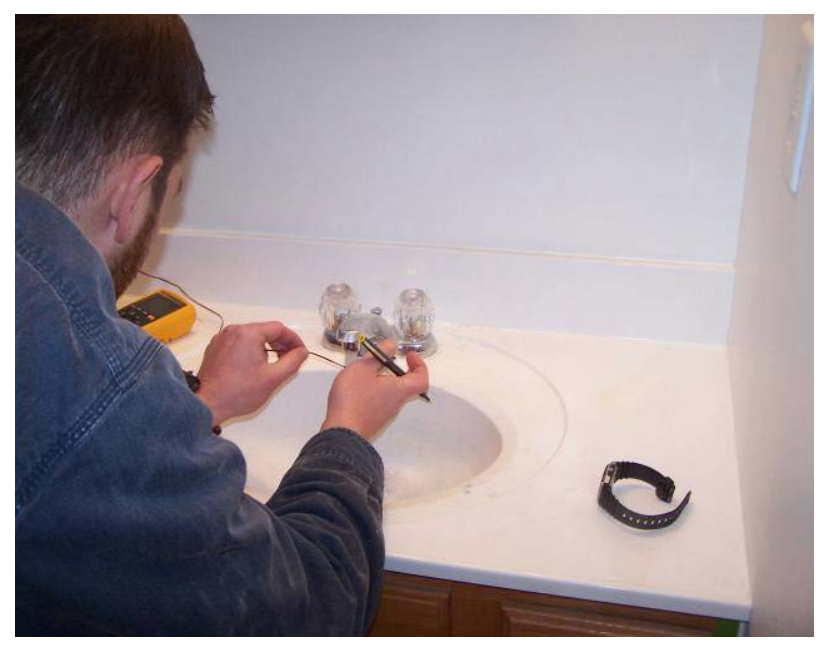

Figure 39. Hot water draw test
During the field test, the solar domestic hot water system was not functioning with a cold storage tank. The hot water draw test at the faucet on Figure 39. Hot water draw test describes the backup tankless water heater only.

The master bathroom faucet was selected as the worst case because it has the longest distance to travel from the water heater. It took 1 minute for the water to warm to $80^{\circ} \mathrm{F}$, and 1 minute and 16 seconds to warm to $106^{\circ} \mathrm{F}$. Further testing is needed when the rest of the houses are brought on line.

Several discussions took place about fixing the solar hot water system. It was fixed and operating properly a week after the field trip. There is concern that the solar hot water system may not perform as designed and the homeowner may be unaware of that. Long-term monitoring and diagnostics are recommended.

\subsection{Duct Leakage Test}

The only distribution duct in the space is on the distribution/transfer fan. Field measurement showed duct leakage of $9 \mathrm{cfm}( \pm 10 \%)$.

- First floor ceiling grille: $90 \mathrm{cfm}$

- Southwest bedroom: $29 \mathrm{cfm}$

- Southeast bedroom: $28 \mathrm{cfm}$

- Northeast bedroom: $24 \mathrm{cfm}$

\subsection{Power Measurement}

The following electrical power measurements were taken on site:

- Monitor space heater standby baseline power (including doorbell, clock, and LED light): $6 \mathrm{~W}$

- Monitor space heater fan on power: $63 \mathrm{~W}$

- Central exhaust fan low speed: $6 \mathrm{~W}$

- Central exhaust fan high speed: $14 \mathrm{~W}$

- First floor bathroom fan on: $17 \mathrm{~W}$

- Distribution/transfer fan on: $11 \mathrm{~W}$ 


\subsection{Conclusions}

On February 16-21, 2009, NREL, Mountain Energy Partnership, and CARB conducted shortterm field tests on a three-bedroom unit in the Wisdom Way Solar Village. The field tests included: a blower door test, Tracer gas test, thermal imaging test, and other miscellaneous tests and measurements.

The blower door tests showed the test house has exceptionally tight construction with 11.2 in. ${ }^{2}$ ELA at 4 Pascal.

The tracer gas tests showed good distribution of combined (mechanical and natural) ventilation throughout all rooms in the three-bedroom test unit when the exhaust ventilation fan works in conjunction with the distribution/transfer fan.

The indoor air temperature overnight measurement showed the space conditions had some deviations from ACCA Manual RS design standards and ASHRAE 55 comfort standards. The space heater, in conjunction with the distribution/transfer fan, is not sufficient to distribute the point heating throughout the house. We recommend supplementary heating backup in the upstairs bedrooms in addition to the point source heating system for acceptable comfort conditions.

We also recommend a better air seal gasket on the attic access door; more hot water draw tests when solar water heating systems are brought online, and long-term diagnostic monitoring of the solar water heating systems. 


\subsection{References}

1. Aldrich, R.A. (2008). Consortium for Advanced Residential Buildings (CARB). 2008 Annual Progress Report Budget Period 1 (BP 1), Appendix X: Cold Climate Case StudyBuilding America 40+\% Cold Initial Community Scale RDI: Wisdom Way Solar Village.

2. American Society of Heating, Refrigerating and Air-Conditioning Engineers, Inc. (2003). ASHRAE 62.2-2003, Ventilation and Acceptable Indoor Air Quality in Low-Rise Residential Buildings, Section 4: Whole Building Ventilation, p. 4.

3. American Society of Heating, Refrigerating and Air-Conditioning Engineers, Inc. (2004). ASHRAE Standard 55 - 2004, Thermal Environmental Conditions for Human Occupancy.

4. Air Conditioning Contractors of America (ACCA) Manual RS. (1997). Comfort, Air Quality and Efficiency by Design. Section 1, pp. 1-9.

5. Barley, D.; Anderson, R.; Hendron, B.; Hancock, E. (2007). A Test Protocol for Room-toRoom Distribution of Outside Air by Residential Ventilation Systems. NREL/TP-55031548. Golden, CO: National Renewable Energy Laboratory.

6. Grieve, P.W. (1991). Measuring Ventilation Using Tracer-Gases. Denmark: Brüel \& Kjær.

7. Pennsylvania Housing Research Center (PHRC). (2006), Builder Brief BB0201. Blower Door Testing. www.pct.edu/wdce/wtc/pdf/Blower-Door-FINAL.pdf. 


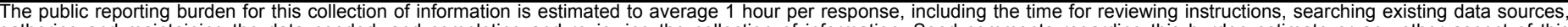

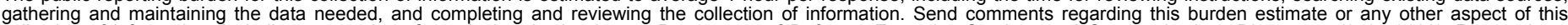

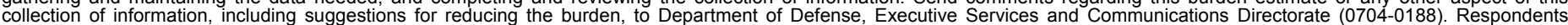

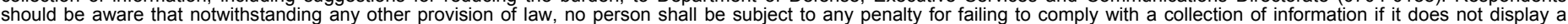

should be aware that notwithstanding

PLEASE DO NOT RETURN YOUR FORM TO THE ABOVE ORGANIZATION.

\section{REPORT DATE (DD-MM-YYYY) May 2009 \\ 2. REPORT TYPE \\ Technical Report}

\section{TITLE AND SUBTITLE}

RDI Development: Wisdom Way Solar Village, Greenfield, Massachusetts Field Test Report
3. DATES COVERED (From - To) 5a. CONTRACT NUMBER

DE-AC36-08-GO28308

5b. GRANT NUMBER
6. AUTHOR(S)

X. Fang, and E. Hancock 5d. PROJECT NUMBER

NREL/TP-550-45865

5e. TASK NUMBER

BET98001

5f. WORK UNIT NUMBER
7. PERFORMING ORGANIZATION NAME(S) AND ADDRESS(ES)

National Renewable Energy Laboratory

1617 Cole Blvd.

Golden, CO 80401-3393
8. PERFORMING ORGANIZATION REPORT NUMBER

NREL/TP-550-45865

9. SPONSORING/MONITORING AGENCY NAME(S) AND ADDRESS(ES)

10. SPONSOR/MONITOR'S ACRONYM(S) NREL

11. SPONSORING/MONITORING AGENCY REPORT NUMBER

12. DISTRIBUTION AVAILABILITY STATEMENT

National Technical Information Service

U.S. Department of Commerce

5285 Port Royal Road

Springfield, VA 22161

13. SUPPLEMENTARY NOTES

14. ABSTRACT (Maximum 200 Words)

The National Renewable Energy Laboratory, Mountain Energy Partnership (a subcontractor of NREL), and the Consortium of Advanced Residential Buildings conducted short-term field tests on a house in the Wisdom Way Solar Village (G3, community scale, $40 \%$ savings level, cold climate). The house design features exceptionally tight construction, highly insulated envelopes, efficient ventilation and space heating design, and on-site renewable energy. NREL conducted field tests to verify that the prototype houses achieve the energy efficiency goal and maintain indoor air quality and comfort. Specifically, the Wisdom Way field test is targeted at verifying the performance of the point source heating, exhaust fan ventilation, and innovative distribution/transfer fan effectiveness in air and heat distribution.

15. SUBJECT TERMS wisdom way solar village; building america; field test; indoor air quality; energy efficiency

\begin{tabular}{|c|c|c|}
\hline $\begin{array}{l}\text { a. REPORT } \\
\text { Unclassified }\end{array}$ & $\begin{array}{l}\text { b. ABSTRACT } \\
\text { Unclassified }\end{array}$ & $\begin{array}{l}\text { c. THIS PAGE } \\
\text { Unclassified }\end{array}$ \\
\hline
\end{tabular}

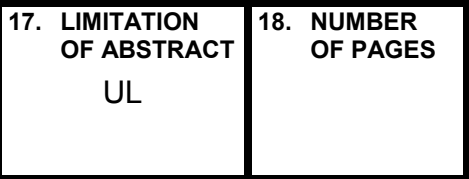

19a. NAME OF RESPONSIBLE PERSON

19b. TELEPHONE NUMBER (Include area code) 